University of Wollongong

Research Online

Faculty of Science, Medicine and Health -

Papers: Part B

Faculty of Science, Medicine and Health

$1-1-2020$

\title{
Five-membered cyclic sulfamidate imines: versatile scaffolds for organic synthesis
}

Quoc Hoang Pham

University of Wollongong, qhp428@uowmail.edu.au

Christopher J. T Hyland

University of Wollongong, chrhyl@uow.edu.au

Stephen G. Pyne

University of Wollongong, spyne@uow.edu.au

Follow this and additional works at: https://ro.uow.edu.au/smhpapers1

\section{Publication Details Citation}

Pham, Q., Hyland, C. J., \& Pyne, S. G. (2020). Five-membered cyclic sulfamidate imines: versatile scaffolds for organic synthesis. Faculty of Science, Medicine and Health - Papers: Part B. Retrieved from https://ro.uow.edu.au/smhpapers1/1572

Research Online is the open access institutional repository for the University of Wollongong. For further information contact the UOW Library: research-pubs@uow.edu.au 


\title{
Five-membered cyclic sulfamidate imines: versatile scaffolds for organic synthesis
}

\begin{abstract}
In recent years, five-membered ring cyclic sulfamidate imines (5H-1,2,3-oxathiazole 2,2-dioxides) have received increasing attention as useful precursors for the stereoselective synthesis of many valuable heterocycles. Bearing a reactive $\mathrm{N}$-sulfonyl imine moiety as part of the stereodefined skeleton, this sulfamidate imine platform has been utilised as a substrate in many reactions, including nucleophilic additions and reductions, to prepare highly functionalised cyclic sulfamidates. In addition, cyclic sulfamidate imines can also readily participate as nucleophiles in many chemical transformations, owing to the reactivity of the acidic proton(s) adjacent to the imine moiety. This short review highlights recent developments involving cyclic sulfamidate imines, including their synthesis and their diastereoselective and enantioselective chemical reactions.
\end{abstract}

\section{Keywords}

synthesis, scaffolds, imines:, organic, versatile, five-membered, cyclic, sulfamidate

\section{Publication Details}

Pham, Q., Hyland, C. J. T. \& Pyne, S. G. (2020). Five-membered cyclic sulfamidate imines: versatile scaffolds for organic synthesis. Organic and Biomolecular Chemistry, Online First 1-19. 


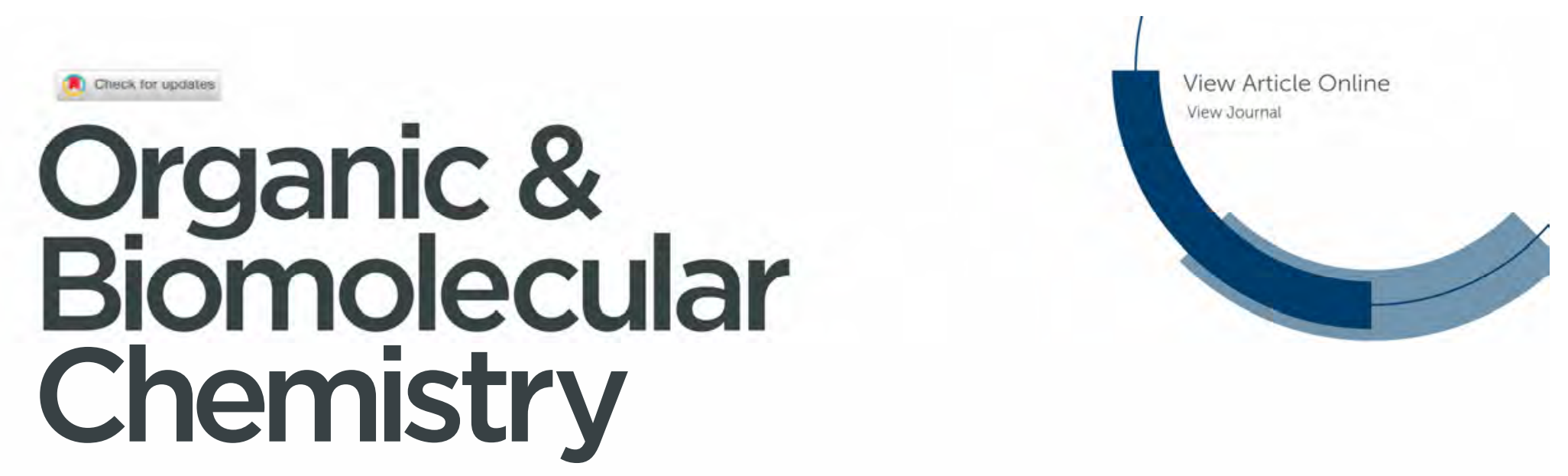

\section{Accepted Manuscript}

This article can be cited before page numbers have been issued, to do this please use: Q. H. Pham, C. J. T. Hyland and S. G. Pyne, Org. Biomol. Chem., 2020, DOI: 10.1039/D0OB01568G.

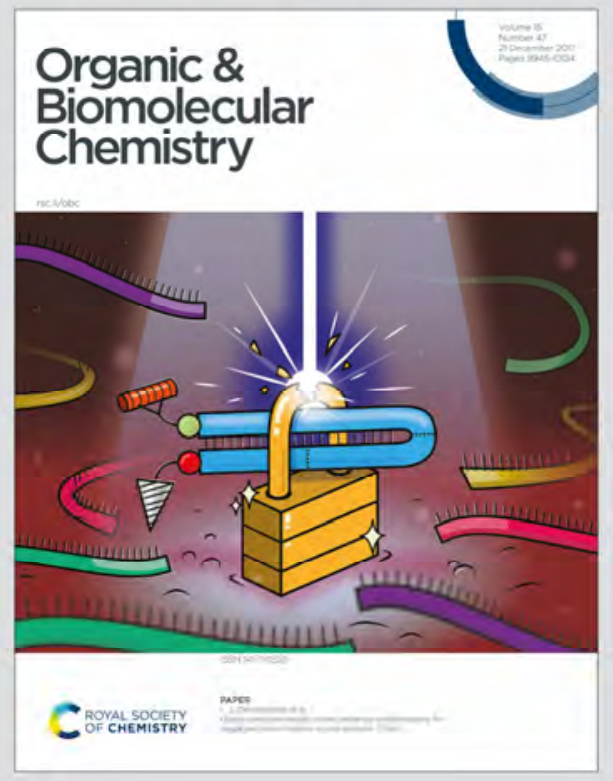

This is an Accepted Manuscript, which has been through the Royal Society of Chemistry peer review process and has been accepted for publication.

Accepted Manuscripts are published online shortly after acceptance, before technical editing, formatting and proof reading. Using this free service, authors can make their results available to the community, in citable form, before we publish the edited article. We will replace this Accepted Manuscript with the edited and formatted Advance Article as soon as it is available.

You can find more information about Accepted Manuscripts in the Information for Authors.

Please note that technical editing may introduce minor changes to the text and/or graphics, which may alter content. The journal's standard Terms \& Conditions and the Ethical guidelines still apply. In no event shall the Royal Society of Chemistry be held responsible for any errors or omissions in this Accepted Manuscript or any consequences arising from the use of any information it contains. 


\title{
ARTICLE
}

\section{Five-membered cyclic sulfamidate imines: versatile scaffolds for organic synthesis}

Received 00th January 20xx, Accepted 00th January 20xx

DOI: $10.1039 / \times 0 \times x 00000 x$

\author{
Quoc Hoang Pham, ${ }^{* a}$ Christopher J. T. Hyland *a and Stephen G. Pyne *a
}

In recent years, five-membered ring cyclic sulfamidate imines (5H-1,2,3-oxathiazole 2,2-dioxides) have received increasing attention as useful precursors for the stereoselective synthesis of many valuable heterocycles. Bearing a reactive $\mathrm{N}$-sulfonyl imine moiety as part of the stereodefined skeleton, this sulfamidate imine platform has been utilised as a substrate in many reactions, including nucleophilic additions and reductions, to prepare highly functionalised cyclic sulfamidates. In addition, cyclic sulfamidate imines can also readily participate as nucleophiles in many chemical transformations, owing to the reactivity of the acidic proton(s) adjacent to the imine moiety. This short review highlights recent developments involving cyclic sulfamidate imines, including their synthesis and their diastereoselective and enantioselective chemical reactions.

\section{Introduction}

Five-membered ring cyclic sulfamidates (formally 1,2,3oxathiazolidine 2,2-dioxides, Figure 1) have emerged as useful synthetic intermediates that had been used extensively for the syntheses of various heterocycles and natural products. The chemistry of this five-membered scaffold is well established, and the synthesis and applications of this heterocyclic scaffold had been extensively summarised. ${ }^{1-4}$ In contrast, the chemistry of the closely related, unsaturated cyclic sulfamidate imine (formally $5 H$-1,2,3-oxathiazole 2,2-dioxide) scaffold is less wellunderstood.

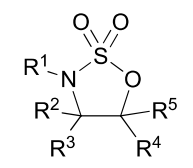

Cyclic sulfamidate

(1,2,3-oxathiazolidine 2,2-dioxide)

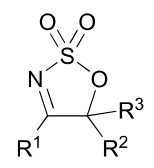

Cyclic sulfamidate imine (5H-1,2,3-oxathiazole 2,2-dioxide)
Figure 1. The general structures of cyclic sulfamidate (left) and the related cyclic sulfamidate imine (right).

In recent years, the stereodefined and reactive cyclic sulfamidate imine scaffold-loaded with an activated imine functionality adjoining a labile stereogenic centre, tied together by a moiety that can be lost as sulfur trioxide-has received increasing attention, being prepared and investigated in a diverse range of research areas (Figure 2). A large portion of these studies have utilised cyclic sulfamidate imines in hydrogenation, addition, and cycloaddition reactions, taking advantage of the reactive imine moiety in a highly efficient and

a. School of Chemistry and Molecular Bioscience, Molecular Horizons Research Institute, University of Wollongong, Wollongong, New South Wales, 2522, Australia.E-mail:qhp428@uowmail.edu.au,chrhyl@uow.edu.au, and spyne@uow.edu.au often stereoselective manner. The presence of a labile adjacent stereocentre allows dynamic kinetic resolutions to take place in some of these processes.

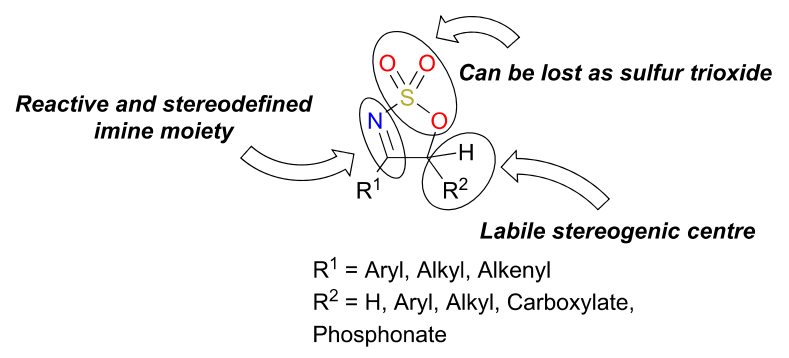

Figure 2. General reactivity of cyclic sulfamidate imines.

As well as allowing for dynamic kinetic resolution to take place, the labile proton at the $\alpha$-position to the imine moiety can be functionalised under basic conditions with electrophiles. In many cases, these $\mathrm{C} 5$-functionalised intermediates can undergo further transformations in a cascade fashion, some of which involving the loss of a molecule of sulfur trioxide.

This short review aims to summarise recent works harnessing this cyclic sulfamidate imine scaffold in synthesis. To distinguish between generic structures and specific compounds, two separate numbering systems were implemented, with the former being numbered by capitalised letter (sometimes followed by a number), while the latter being numerically numbered exclusively.

\section{Synthesis of cyclic sulfamidate imines}

There are several methods for the preparation of the fivemembered ring cyclic sulfamidate imines from the corresponding $\alpha$-hydroxyketone precursors (A). Among these, the most frequently employed approach utilises sulfamoyl 
chloride 1, which is generated in situ from chlorosulfonyl isocyanate (CSI) and formic acid (Scheme 1).

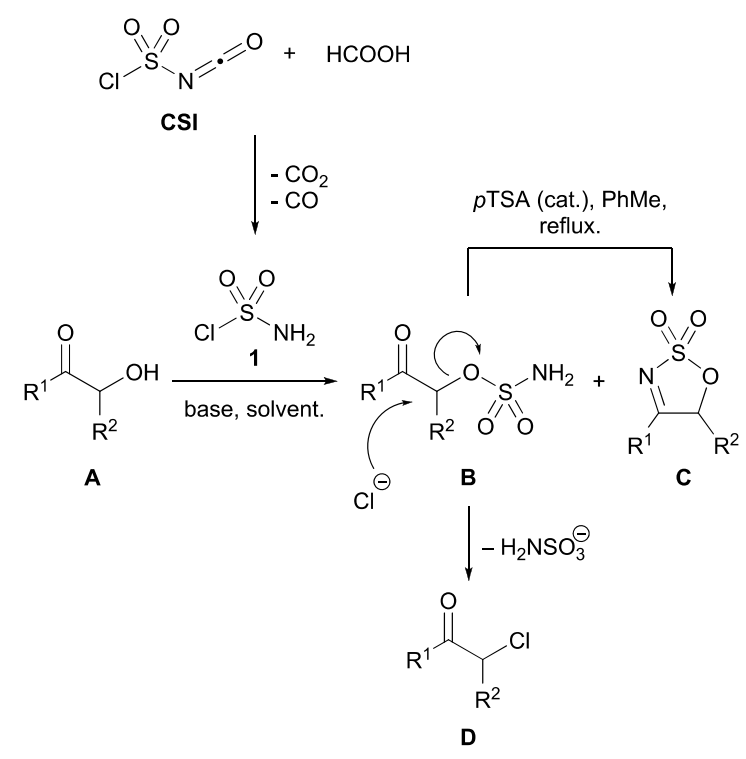

Scheme 1. Synthesis of 5H-1,2,3-oxathiazole 2,2-dioxides C via the CSI approach.

Although being widely employed to prepare cyclic sulfamidate imines, this approach suffers from various drawbacks. The reaction between CSI and formic acid is usually performed as a neat reaction and is highly exothermic, accompanied by violent gas evolution. As this reaction progresses, the mixture also solidifies, greatly reducing the efficiency. Addition of solvent, usually acetonitrile ( $\mathrm{MeCN}$ ), is often required at this stage to achieve complete conversion to the desired reagent $1 .{ }^{5}$ Alternatively, the solid sulfamoyl chloride 1 generated can be stored at $-15^{\circ} \mathrm{C}$ for future usage. ${ }^{6}$

The reaction between $\alpha$-hydroxyketone $\mathbf{A}$ and $\mathbf{1}$ is usually carried out in $\mathrm{MeCN}$ in the presence of base, usually pyridine. Some variants of this approach employ $\mathrm{N}, \mathrm{N}$-dimethylacetamide (DMA) as an alternative to pyridine, sometimes also taking up the role of the solvent (Scheme 1). ${ }^{7}$ Regardless of the base and the solvent employed, this reaction frequently yields a mixture of products, including the acyclic sulfamidate ketone $\mathbf{B}$, the cyclic sulfamidate imine $\mathbf{C}$, and the undesired $\alpha$-chloroketone $\mathbf{D}$ by-product-which can be formed by displacement of the sulfamidate moiety of $\mathbf{B}$ by a chloride anion. ${ }^{8}$ The crude reaction material obtained after work-up needs to be heated at reflux in toluene with a catalytic amount of $p$-toluenesulfonic acid ( $p$ TSA) for several hours with azeotropic removal of water. This is followed by a second work-up and chromatographic purification to remove by-product $\mathbf{D}$ from the desired product C.

Realising the various issues suffered by this synthetic pathway, two notable alternatives have been proposed. In 2011, the K.-I. Lee group outlined a different approach to cyclic sulfamidate imines from $\alpha$-hydroxyketones $\mathbf{A}$ using sulfamide $\mathbf{2}$, which is both more stable and more readily available compared to sulfamoyl chloride $1 .{ }^{9}$ In this one-pot protocol, A can be reacted with $\mathbf{2}$ directly in $p$-xylene at reflux, affording the desired cyclic imine $\mathbf{D}$ in comparable yields to those prepared via sulfąmoyl chloride 1 (Scheme 2). ${ }^{9,10}$ DOI: 10.1039/D0OB01568G

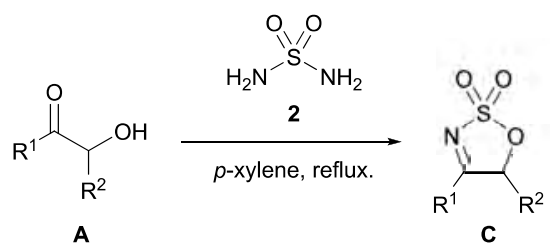

Scheme 2. Synthesis of 5H-1,2,3-oxathiazole 2,2-dioxides $\mathrm{C}$ using sulfamide.

The McLaughin group, in 2013, reported an improved CSI approach for the synthesis of cyclic sulfamidate imines. ${ }^{8}$ With the aim of devising a practical, large scale synthesis of a drug candidate via a key cyclic sulfamidate imine intermediate (vide infra), McLaughin and co-workers outlined an improved synthesis of this scaffold based on the CSI approach. In the revised protocol (Scheme 3), $\boldsymbol{N}$-Boc-1 was generated from the addition reaction of CSI with a slight excess of tert-butyl alcohol $(t-\mathrm{BuOH})$. The reaction involved no gas evolution and can be carried out in a solution, allowing more efficient control over the exotherm. Triethylamine $\left(\mathrm{Et}_{3} \mathrm{~N}\right)$ was employed instead of pyridine, taking advantage of the poor solubility of its hydrochloride salt to minimise the presence of chloride anion in the reaction mixture, therefore negating the formation of byproduct D. Furthermore, the precipitated triethylamine hydrochloride salt could be efficiently removed by a simple aqueous work-up, which also allows for a direct processing of the acyclic intermediate $\mathbf{N}$-Boc-B in same reaction solvent at elevated temperature to furnish cyclic imine $\mathbf{C}$.

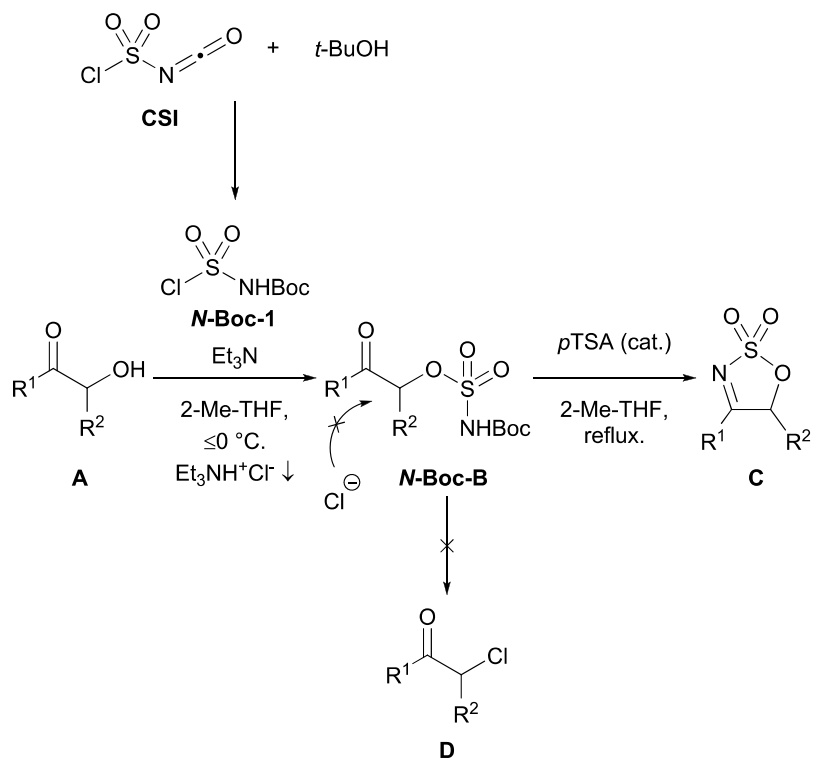

Scheme 3. Synthesis of 5H-1,2,3-oxathiazole 2,2-dioxides $\mathrm{C}$ via a revised CSI approach.

\section{Addition reactions to the imine moiety}

3.1. Catalytic asymmetric hydrogenation 
Taking advantage of the prochiral, activated imine, many studies focusing on the development of asymmetric hydrogenations of the cyclic sulfamidate imine had been disclosed. A number of combinations of transition metals and chiral ligands were employed, all of which can furnish the desired sulfamidate in high yields and enantioselectivities.

In 2008, the Zhou group reported a Pd-catalysed asymmetric hydrogenation of cyclic imines, employing 4-substituted cyclic sulfamidate imines $\mathbf{C 1}$ and $\mathbf{C 2}$ as one of their two substrate classes (Scheme 4a). ${ }^{5}$ Under the optimised reaction conditions, using $\mathrm{Pd}(\mathrm{TFA})_{2}$ as the Pd-source and $(S, S)$-f-Binaphane as ligand, a range of 4-aryl (C1) and 4-alkyl imines (C2) were efficiently reduced to the corresponding cyclic sulfamidates E1 and E2, respectively. Aryl imines $\mathbf{C} \mathbf{1}$ bearing a range of electrondonating or electron-withdrawing groups (EDGs and EWGs, respectively) at various positions on the aromatic ring were all well tolerated, affording the desired products in high yields and $e e^{\prime}$ s. Some 4-alkyl imines $\mathbf{C 2}$ were examined $(\mathrm{R}=\mathrm{Me}, t$-Bu, and $n$-Hex), and all were found to be competent substrates. The authors also reported the procedure could be carried out in air with comparable efficacy and enantioselectivity.

Recently, the Zhang group reported an Ir-catalysed asymmetric hydrogenation of cyclic sulfamidate imines $\mathbf{C 1}$ and $\mathbf{3}$, utilising their in-house developed ZhaoPhos ligand (Scheme 4b). ${ }^{11} \mathrm{~A}$ wide range of 4-aryl imines $\mathbf{C} 1$ with diverse electronic and steric properties were studied, all of which furnished the desired products E1 in high yields and excellent enantioselectivities. The related 2-naphthyl and 2-thienyl substrates were also found to be well tolerated in this procedure, delivering the corresponding products in comparable efficacy (97-98\% yield, $96-97 \%$ ee). Only one 4-alkyl substrate 3 was examined ( $R=B n)$, and although the desired cyclic sulfamidate $\mathbf{4}$ was obtained in high yield (98\%), the enantiomeric excess ( $73 \%$ ee) was subpar compared to the aryl substrates. a)

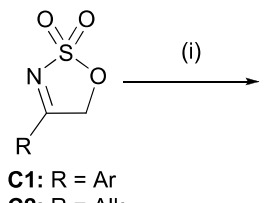

C2: $\mathrm{R}=$ Alk

b)

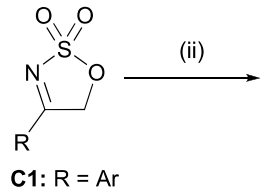

3: $R=B n$

c)

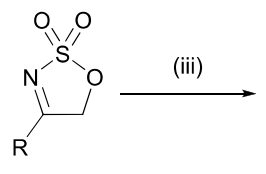

C1: $R=A r$

C2: $R=$ Alk

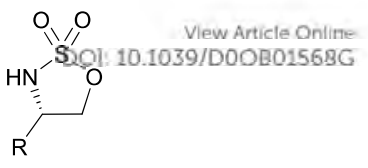

$E 1: R=A r$

6 examples: $94-99 \%$

up to $97 \%$ ee

E2: $\mathrm{R}=$ Alk

3 examples: $97-99 \%$

up to $97 \%$ ee

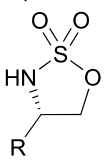

E1: $\mathrm{R}=\mathrm{Ar}$

15 examples: 94-99\%

up to $99 \%$ ee

4: $\mathrm{R}=\mathrm{Bn}$ :

$98 \%, 73 \%$ ee

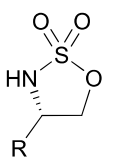

E1: $\mathrm{R}=\mathrm{Ar}$

14 examples: $65-99 \%$

up to $>99 \%$ ee

E2: $\mathrm{R}=$ Alk

2 examples: $96-98 \%$

up to $92 \%$ ee

Reagents: (i) $\mathrm{Pd}\left(\mathrm{CF}_{3} \mathrm{CO}_{2}\right)_{2}(2.0 \mathrm{~mol} \%),(\mathrm{S}, \mathrm{S})$-f-Binaphane $(2.4 \mathrm{~mol} \%$ ), $\mathrm{H}_{2}(600 \mathrm{psi})$, TFE, rt.

(ii) $[\mathrm{Ir}(\mathrm{COD}) \mathrm{Cl}]_{2}(0.5 \mathrm{~mol} \%)$, ZhaoPhos (1.1 mol\%), $\mathrm{H}_{2}(60 \mathrm{psi}), \mathrm{CH}_{2} \mathrm{Cl}_{2}$, rt (iii) $\mathrm{Ni}(\mathrm{OAc})_{2}(1.0 \mathrm{~mol} \%),(S, S)-\mathrm{Ph}-\mathrm{BPE}(1.0 \mathrm{~mol} \%)$, $\mathrm{H}_{2}(60 \mathrm{~atm}), \mathrm{CF}_{3} \mathrm{CH}_{2} \mathrm{OH}, 80^{\circ} \mathrm{C}$.

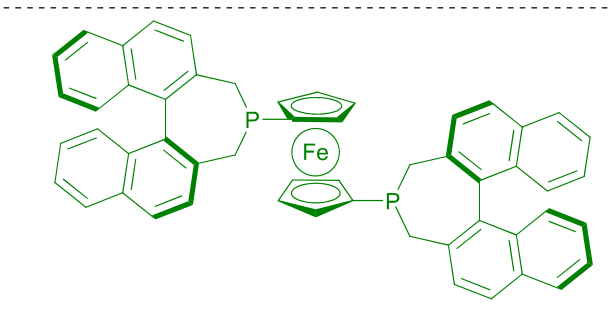

$(S, S)$-f-Binaphane
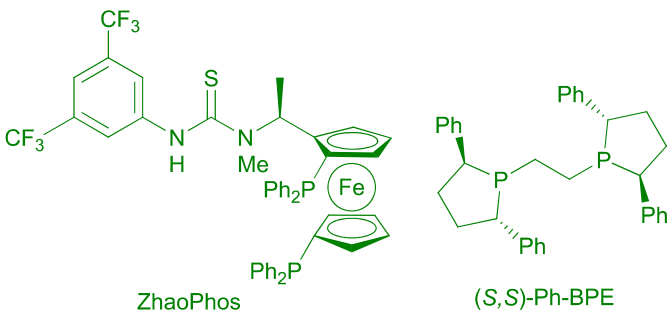

Scheme 4. a) The Pd-catalysed asymmetric hydrogenation reaction of cyclic sulfamidate imines $\mathbf{C 1 / C 2}$. b) The Ir-catalysed asymmetric hydrogenation reaction of cyclic sulfamidate imines $\mathbf{C} 1 / \mathbf{3}$. c) The Ni-catalysed asymmetric hydrogenation reaction of cyclic sulfamidate imines $\mathbf{C 1 / C 2}$.

In the same year, the Zhang group also disclosed a Ni-catalysed asymmetric hydrogenation of 4-aryl and 4-alkyl imines $\mathbf{C 1}$ and C2, using the commercially available $(S, S)$-Ph-BPE as ligand (Scheme $4 c$ ). ${ }^{12} \mathrm{~A}$ wide range of 4 -aryl cyclic imines C1 were employed as substrates, with the aryl group bearing various EDGs and EWGs at the ortho-, meta-, or para-positions. Neither 
the electronic nor the steric properties of these aryl substrates seemed to have a significant effect on the yields and enantioselectivities of E1. The related 2-naphthyl- and 2thienyl-substituted imines were examined, and while the naphthyl substrate was well tolerated (97\%, 92\% ee), a significantly diminished yield was reported for the thienyl derivative, albeit the enantioselectivity was high $(55 \%, 95 \%$ ee $)$. Two alkyl imines C2 ( $R=\mathrm{Me}$ and Et) were found to be compatible substrates, furnishing the corresponding products E2 in high yields (96-98\%) and good to high enantioselectivities $(83-92 \%$ ee). Notably, the efficiency of this Ni-catalysed asymmetric hydrogenation protocol was on par with those employing a more costly catalyst. 5,11

\subsection{Catalytic symmetric transfer hydrogenation/Asymmetric transfer hydrogenation-Dynamic kinetic resolution}

A significant number of studies involving the asymmetric transfer hydrogenation (ATH) of cyclic sulfamidate imines had been reported, the vast majority of which employed a chiral $\mathrm{Rh}$ (III) complex along with a homogeneous formic acid/ $\mathrm{Et}_{3} \mathrm{~N}$ mixture as the hydrogen source, avoiding the hazards associated with the use of molecular hydrogen gas at high pressure.

In 2010, H.-K. Lee and co-workers reported their study on the ATH reaction of sulfamidate imines $\mathbf{C 1}$ and $\mathbf{C 2}$ (Scheme 5a). ${ }^{7}$ In this work, $\operatorname{RhCl}[(R, R)$-TsDPEN $] C$ * was employed as the catalyst, while a mixture of $\mathrm{FA} / \mathrm{Et}_{3} \mathrm{~N}(5: 2)$ was used as the hydrogen source. Under the optimised reaction conditions, a wide range of aryl-substituted cyclic sulfamidate imines C1 bearing a diverse range of substituents on the aryl moiety were examined. Imines $\mathbf{C 1}$ bearing substituents at the meta- or parapositions of the aryl ring all underwent the reduction reaction efficiently, affording the corresponding cyclic sulfamidates E1 in high yields and enantioselectivities. These results are in agreement with those reported independently by the K.-I. Lee group. ${ }^{9}$ In comparison, when subjecting ortho-substituted aryl imines $\mathbf{C 1}$ to the reaction conditions, a significant decline in enantioselectivities of E1 was reported, with an ee as low as $16 \%$ observed. In addition to this observation, when two 4-alkyl imine C2 substrates were examined ( $\mathrm{R}=n$-Hex and $t$-Bu), the sterically hindered $t$-Bu-substituted imine failed to deliver the corresponding product. These observations seemed to indicate that this procedure is sensitive to steric bulk, especially with 4alkyl imines $\mathbf{C 2}$. a)

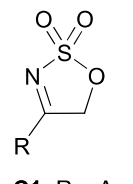

(i)

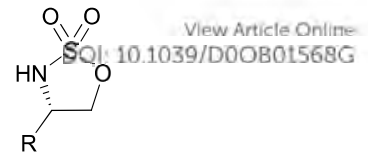

C1: $\mathrm{R}=\mathrm{Ar}$

C2: $\mathrm{R}=$ Alk

$\mathrm{E1}: \mathrm{R}=\mathrm{Ar}$

16 examples: $91-99 \%$

up to $99 \%$ ee

E2: $R=$ Alk

2 examples: $0-96 \%$

b)
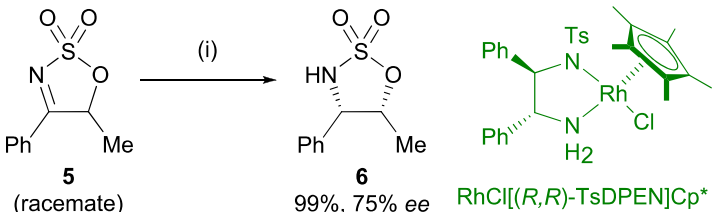

6

99\%, $75 \%$ ee $\operatorname{RhCl}[(R, R)-T s D P E N] C p^{*}$

Reagents: (i) RhCII(R,R)-TsDPEN]Cp* $(0.5 \mathrm{~mol} \%)$, $\mathrm{HCOOH} / \mathrm{Et}_{3} \mathrm{~N}(5: 2)$, EtOAc, rt.

Scheme 5. a) The Rh-catalysed ATH reaction of 4-substituted cyclic sulfamidate imines C1/C2. b) The Rh-catalysed ATH-DKR reaction of 5-methyl-4-phenyl cyclic sulfamidate imine 5.

In this study, H.-K. Lee et al. also addressed an accompanying dynamic kinetic resolution (DKR) when the disubstituted 5methyl-4-phenyl substrate 5 was subjected to the ATH reaction conditions (Scheme 5b). ${ }^{7}$ The author noted the exclusive formation of the cis-product $\mathbf{6}$, suggesting the addition of hydrogens to the imine bond occurred from the less hindered face of the sulfamidate imine ring. Further investigation demonstrated that the $\mathrm{FA} / \mathrm{Et}_{3} \mathrm{~N}$ mixture is responsible for the rapid epimerisation of $\mathbf{5}$, while the stereochemical outcome of the reaction is governed by the chirality of the Rh complex. The ATH-DKR procedure reported here for imine $\mathbf{5}$ would be further studied by the group in subsequent investigations.

The H.-K. Lee group next expanded the scope of the ATH-DKR procedure to 4,5-diaryl cyclic sulfamidate imines C3 (Scheme 6). ${ }^{10}$ Consistent with the results previously observed, no transproduct was obtained, and the chirality of the employed catalyst dictated the stereochemical outcome of the reaction. A wide range of imines $\mathbf{C} 3$ were examined, most of which had the same substituents at the $C 4$ and $C 5$ positions. ${ }^{7}$ Overall, these reactions tolerated aryl groups bearing either EDG or EWG at either the meta- or para-positions, furnishing the desired products E3 in high yields and enantioselectivities. One exception was the 4,5-bis( $p$-anisolyl) substrate, where no reaction occurred even after an extended period of time. In comparison, when an ortho-substituted substrate was studied, the desired product was obtained in significantly diminished ee (22\%), albeit in high yield (99\%), which was consistent with prior findings. ${ }^{7}$ 


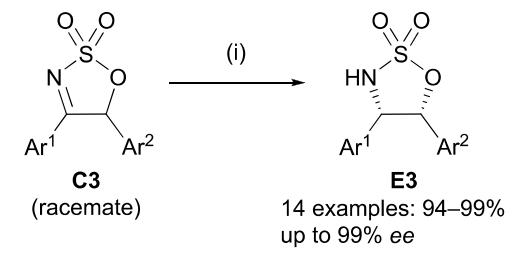

Reagents: (i) $\mathrm{RhCl}[(R, R)-\mathrm{TsDPEN}] \mathrm{Cp}^{*}(0.5 \mathrm{~mol} \%)$, $\mathrm{HCOOH} / \mathrm{Et}_{3} \mathrm{~N}(5: 2)$, EtOAc, rt.

Scheme 6. The Rh-catalysed ATH-DKR reaction of 4,5-diaryl cyclic sulfamidate imines C3

A report from the H.-K. Lee group in 2014 highlighted the use of 5-carboxylate ester cyclic sulfamidate imines $\mathbf{C 4}$ and $\mathbf{C 5}$ in their previously developed ATH-DKR procedure (Scheme 7). ${ }^{13}$ The protocol was found to tolerate a wide range of meta- and parasubstituted aryl imines C4, as well as heteroaryl substituted imines, furnishing the desired cyclic sulfamidate products E4 in high yields and high enantioselectivities. Consistent with previous observations, when the ortho-tolyl substrate was studied, the desired product was obtained in diminished yield $(20 \%))^{7,10}$ However, adjusting the $\mathrm{FA} / \mathrm{Et}_{3} \mathrm{~N}$ ratio to $1: 1$ allowed for an efficient conversion of this substrate to the desired product $(95 \%, 92 \% e e)$, albeit taking significantly longer reaction time compared to other substrates. Several 4-alkyl imines C5 were employed as substrates $\left(\mathrm{R}^{1}=n\right.$ - $\mathrm{Pr}, 2$-phenylethyl, $c$-Hex $)$, and it was observed that as the steric bulk of the alkyl group increased, both the yields and enantioselectivities of E5 declined. Variation of the ester moiety $R^{2}$ showed that this substituent had no significant impact on the reaction efficacy.

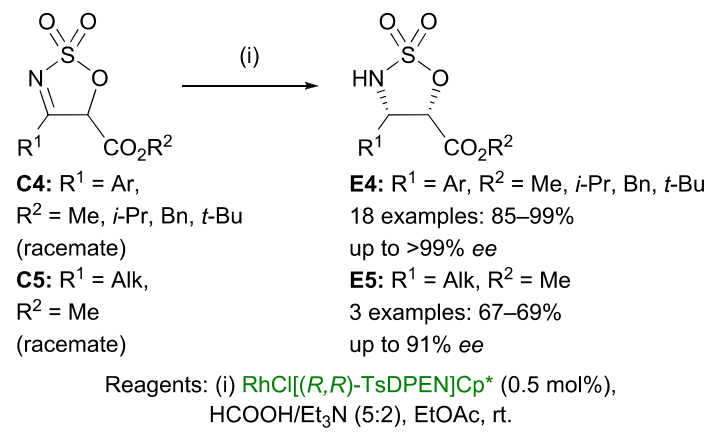

Scheme 7. The Rh-catalysed ATH-DKR reaction of 4-substituted-5-carboxylcate ester cyclic sulfamidate imines C4/C5.

In the same year, the Haraguchi group-with the aim of developing a reusable heterogenous chiral catalyst-published their work on the ATH reaction using a polymer-immobilised chiral Ir-complex (Scheme 8). ${ }^{14}$ In this work, imine 7 was employed to evaluate the efficacy of chiral ligand $L_{\text {polymer }}$ in two ATH processes, catalysed by $\operatorname{Ir}($ III) and Rh(III), respectively. In both cases, 7 was reduced efficiently, delivering the desired product 8 in high yields. However, while a racemate was afforded when the $\operatorname{Ir}(\mathrm{III})$ catalyst was employed, the Rhcatalysed process yielded the cyclic sulfamidate $\mathbf{8}$ in high enantioselectivity, while also being slightly higher-yielding. These results were consistent with those observed by $\mathrm{H}$.-K. Lee et al. previously. $7,10,13$
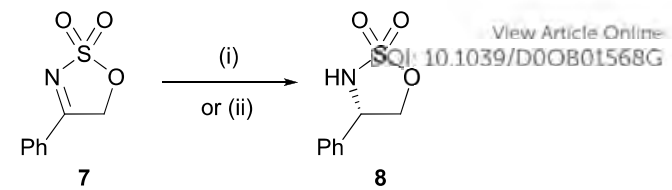

$\mathrm{M}=\operatorname{Ir}: 90 \%, 0 \% \theta \theta$

$\mathrm{M}=\mathrm{Rh}: 97 \%, 95 \%$ ee

Reagents: (i) $\left[\mathrm{IrCl}_{2} \mathrm{Cp}^{*}\right]_{2}(0.5 \mathrm{~mol} \%), \mathrm{L}_{\text {polymer }}(1.2 \mathrm{~mol} \%)$, $\mathrm{HCOOH} / \mathrm{Et}_{3} \mathrm{~N}(5: 2), \mathrm{CH}_{2} \mathrm{Cl}_{2}$, rt.

(ii) $\left[\mathrm{RhCl}_{2} \mathrm{Cp}^{*}\right]_{2}(0.5 \mathrm{~mol} \%), \mathrm{L}_{\text {polymer }}(1.2 \mathrm{~mol} \%)$, $\mathrm{HCOOH} / \mathrm{Et}_{3} \mathrm{~N}(5: 2), \mathrm{CH}_{2} \mathrm{Cl}_{2}$, rt.

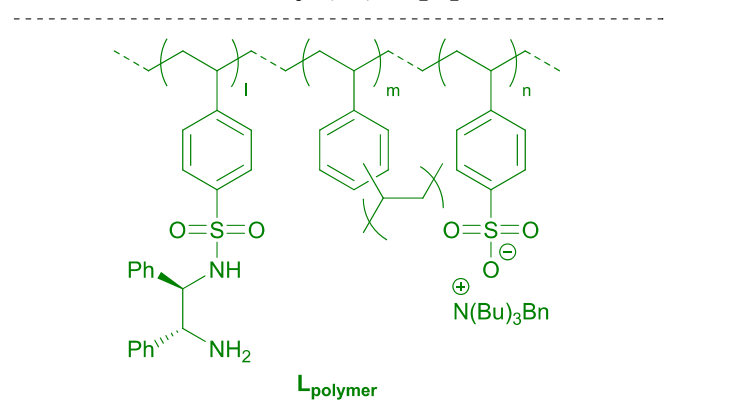

Scheme 8. The Ir- and Rh-catalysed ATH reaction of 4-phenyl cyclic sulfamidate imine $\mathbf{7}$ employing a polymer-immobilised chiral ligand.

In 2015, the H.-K. Lee group reported their implementation of the ATH-DKR procedure to 5-phosphonate imines $\mathbf{C 6}$ and $\mathbf{C 7}$ (Scheme 9a). ${ }^{15}$ A wide range of 4-aryl imines $\mathbf{C 6}$ were studied, and the reaction was found to tolerate many EDGs and EWGs situated at the meta- and para-positions on the aromatic ring, furnishing the corresponding products E6 in high yields and enantioselectivities. Similarly, two 4-heteroaryl substrates $\left(R^{1}=\right.$ 2-furyl and 2-thienyl) were found to be competent substrates (90\%, 97-99\% ee). The reaction of an ortho-substituted imine was sluggish $\left(\mathrm{R}^{1}=2-\mathrm{FC}_{6} \mathrm{H}_{4}\right)$, delivering the product in significantly lowered yield (42\%) and ee (42\%). However, when subjecting this substrate to a slightly modified reaction conditions ( $\mathrm{FA} / \mathrm{Et}_{3} \mathrm{~N}=1: 1$ ), both the yield and enantioselectivity were improved significantly $(95 \%, 81 \% e e)$. The reactions of $4-$ alkyl substrates $\mathbf{C 7}$ were found to be sensitive to the steric bulk of the substituents, consistent with previous reports. ${ }^{7,10,13}$ Notably, when the 4-styryl substrate 9 was subjected to the reaction conditions, it was observed that the conjugated styryl $\mathrm{C}=\mathrm{C}$ bond can also be reduced, resulting in a 1:1 mixture of 4styryl and 4-(2-phenylethyl) cyclic sulfamidates (10 and 11, respectively) being obtained, in a combined yield of $98 \%$ (Scheme 9b). 
a)<smiles>[R12]OC1OS(=O)(=O)N=C1[R]</smiles><smiles>CC</smiles>

C6: $R^{1}=A r$

(racemate) C7: $\mathrm{R}^{1}=$ Alk (racemate)

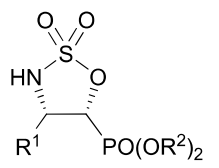

E6: $R^{1}=A r$

14 examples: $90-99 \%$

up to $>99 \%$ ee

E7: $\mathrm{R}^{1}=$ Alk

5 examples: $35-99 \%$

up to $97 \%$ ee

b) 0,0
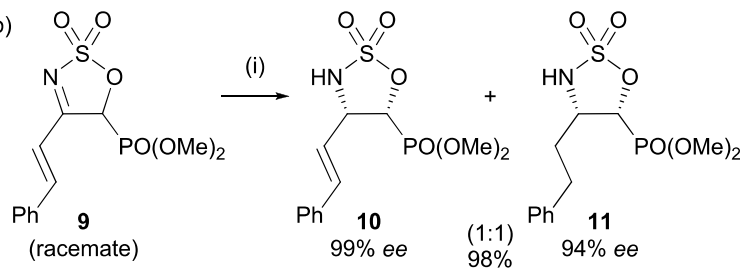

Reagents: (i) RhCI[(R,R)-TsDPEN]Cp* $(0.5 \mathrm{~mol} \%)$, $\mathrm{HCOOH} / \mathrm{Et}_{3} \mathrm{~N}(5: 2)$, EtOAc, rt

Scheme 9. a) The Rh-catalysed ATH-DKR reaction of 4-substituted-5-phosphonate cyclic sulfamidate imines $\mathbf{C 6 / C 7}$. b) The Rh-catalysed ATH-DKR reaction of 4-styryl-5 phosphonate cyclic sulfamidate imine 9 .

In 2018, the H.-K. Lee group revisited the ATH-DKR reaction of 4-substituted-5-alkyl cyclic sulfamidate imine substrates $\mathbf{C} 8$ and 12 that was first reported eight years prior (Scheme 10). ${ }^{16}$ The reaction conditions, which were applied in all prior works, were revised. ${ }^{6,7,10,13,15}$ A stronger base, DBU, was employed in conjunction with FA (FA/DBU $=1: 1)$ to facilitate the rate of racemisation of the 5 -alkyl imine substrate, which is inherently less labile compared to the 5-aryl (C3, Scheme 6), 5-carboxyl (C4 and $\mathbf{C 5}$, Scheme 7), and 5-phosphonate (C6, C7, and 9, Scheme 9) imine analogues. Under the new set of conditions, a range of 4-substituted-5-alkyl imines were studied. Consistent with previous findings, various 4-aryl imines $\mathbf{C 8}$ bearing a range of substituents at the meta- and para-positions on the aryl ring were well tolerated, delivering the corresponding products E8 in high yields and enantioselectivities. Employing two orthosubstituted substrates ( $\mathrm{R}=2-\mathrm{Cl}-\mathrm{Ph}$ and $2-\mathrm{Me}-\mathrm{Ph}, \mathrm{Alk}=\mathrm{Me})$ resulted in a sharp decline in enantioselectivities (53 and $88 \%$ $e e$, respectively). Several 4-heteroaryl substrates were studied, all of which were found to be competent substrates (yields $91-$ $94 \%, 95$ to $>99 \%$ ee). A single 4,5-dialkyl substrate 12 was tested $(\mathrm{R}=n-\mathrm{Bu}, \mathrm{Alk}=\mathrm{Me})$ and was well tolerated, furnishing the desired product 13 in good yield (91\%) and high enantioselectivity $(95 \% \mathrm{ee})$. The nature of the 5 -alkyl group seemed to have little effect on either the yields or the stereochemical outcomes of these reactions.

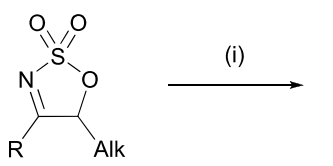

$$
\begin{aligned}
& \text { C8: } \mathrm{R}^{1}=\mathrm{Ar} \\
& \text { (racemate) } \\
& \text { 12: } \mathrm{R}^{1}=n-\mathrm{Bu}, \mathrm{Alk}=\mathrm{Me} \\
& \text { (racemate) }
\end{aligned}
$$

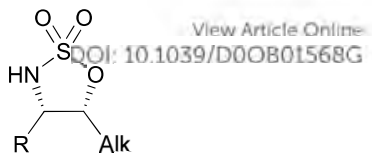

E8: $R^{1}=A r$

25 examples: $90-99 \%$

up to $>99 \%$ ee

13: $\mathrm{R}^{1}=n-\mathrm{Bu}, \mathrm{Alk}=\mathrm{Me}$

$91 \%, 95.2 \%$ ee

Reagents: (i) $\mathrm{RhCl}[(R, R)-\mathrm{TsDPEN}] \mathrm{Cp}^{*}(0.5 \mathrm{~mol} \%)$, $\mathrm{HCOOH} / \mathrm{DBU}(1: 1), \mathrm{MeCN}$, rt.

Scheme 10. The Rh-catalysed ATH-DKR reaction of 4-substituted-5-alkyl cyclic sulfamidate imines $\mathbf{C 8 / 1 2}$.

\subsection{Nucleophilic addition/Metal-catalysed nucleophilic addition}

Many nucleophilic addition reactions of cyclic sulfamidate imines had been reported, the majority of which are highly efficient asymmetric protocols employing transition metal catalysts (e.g. Rh and Pd) with various forms of organoboron reagents.

The reaction of 4-phenyl (7) and 4-methyl (14) cyclic sulfamidate imines with Grignard reagents to give quaternary cyclic sulfamidates $\mathbf{F}$ was investigated by Chang and Lee (Scheme 11). ${ }^{17}$ The two substrates were reacted with several bromo- and iodo-Grignard reagents, and the efficiency of the reaction was found to be strongly dependent on the nature of the carbon nucleophile. Overall, $\mathrm{sp}^{3}$-hybridised carbon nucleophiles tended to give higher yields compared to their $\mathrm{sp}^{2}$ and sp-hybridised counterparts. Investigating this discrepancy in performance, the authors noted a competitive deprotonation process occurring when $\mathrm{sp}^{2}$ - and $\mathrm{sp}$-hybridised nucleophiles were employed, indicated by the presence of a monodeuterated starting material $\mathbf{7}$ following a deuterium oxide quench.

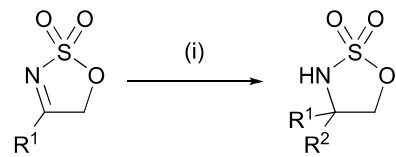

$$
\begin{aligned}
& \text { 7: } R^{1}=P h \\
& \text { 14: } R^{1}=M e
\end{aligned}
$$$$
\mathbf{F}
$$$$
\text { Reagents: (i) } \mathrm{RMgX}\left(1.2 \text { equiv.), MTBE, } 0{ }^{\circ} \mathrm{C}\right.
$$

Scheme 11. The reaction of 4-substituted cyclic sulfamidate imines 7 and 14 with Grignard reagents.

In 2013, the K.-I. Lee group reported a Cu-catalysed Grignard addition to 4-aryl cyclic sulfamidate imines to prepare gemdiaryl sulfamidates (Scheme 12). ${ }^{18}$ Under the optimised reaction conditions, several 4-aryl sulfamidate imines were studied, and it was found that an imine $\mathbf{C 1}$ bearing an electronpoor aryl moiety ( $\mathrm{Ar}=4-\mathrm{Br}-\mathrm{Ph}$ ) furnished the corresponding 4diaryl products $\mathbf{F} \mathbf{1}$ in significantly lowered yields compared to the electron rich $\mathbf{C 1}$ counterparts ( $\mathrm{Ar}=\mathrm{Ph}$ and 2-OMe-Ph). Two related substrates, 4-naphthyl and 4-furyl imines, were tested and both were found to be competent substrates, delivering products $\mathbf{F 1}$ in moderate to good yields. The electronic properties of the aryl Grignard reagents also have a significant 
impact on the outcomes of these reactions, with those bearing either a 3-OMe or a 4-F group resulting in a sharp decline in yields. Notably, alkyl ( $R=E t$, allyl, and $B n)$ and alkenyl $(R=$ vinyl) Grignard reagents can also be used, requiring only a change of solvent from $\mathrm{CH}_{2} \mathrm{Cl}_{2}$ to THF. Under the slightly modified reaction conditions, their reactions with 4-phenyl cyclic sulfamidate imine $\mathbf{C 1}$ furnished the corresponding products in moderate to high yields.

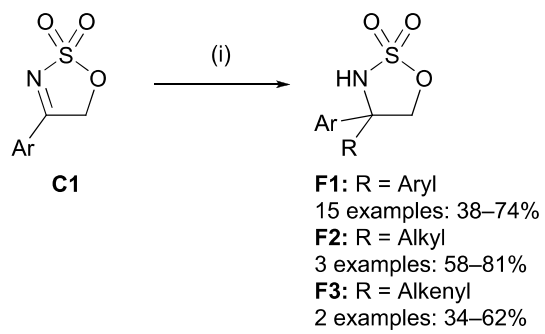

Reagents: (i) $\mathrm{RMgBr}$ (1.5 equiv.), Cu(OTf $)_{2}(5.0 \mathrm{~mol} \%)$, $\mathrm{CH}_{2} \mathrm{Cl}_{2}$ or THF, rt.

Scheme 12. The Cu-catalysed Grignard additions to 4-aryl cyclic sulfamidate imines C1.

A Rh-catalysed nucleophilic allylation reaction of cyclic imines using potassium allyltrifluoroborate was reported by Lam and co-workers in 2012, in which the cyclic sulfamidate imine 14 was employed as substrate (Scheme 13). ${ }^{19}$ In their work, Lam et al. employed their in-house developed chiral diene ligand L1, with the substrate scope mainly focused of cyclic aldimines. Implementation of ketimine $\mathbf{1 4}$ as substrate required slightly harsher reaction conditions compared to those employed for the aldimine substrates, and the reaction time was significantly longer. Regardless, the allylated product $\mathbf{1 5}$ was obtained in high yield and high enantiomeric excess. The harsher reaction conditions and the prolonged reaction time required is probably due to the inherently less reactive nature of a ketimine compared to an aldimine. The incorporation of an allyl group is particularly interesting due to the versatility of this group toward subsequent functionalisation.

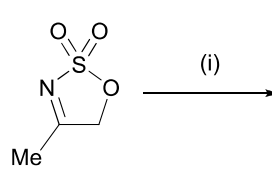

14

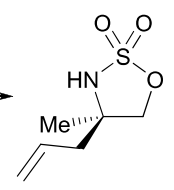

15

$83 \%, 93 \%$ ee

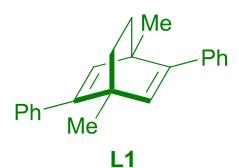

L1

Reagents: (i) Potassium allyltrifluoroborate (1.5 equiv.), $\left[\{\mathrm{Rh}(\mathrm{L} 1) \mathrm{Cl}\}_{2}\right](1.5 \mathrm{~mol} \%), \mathrm{MeOH}(5.0$ equiv. $)$, dioxane, $80^{\circ} \mathrm{C}$.

Scheme 13. The Rh-catalysed nucleophilic allylation of 4-methyl cyclic sulfamidate imine 14.

In 2013, Hayashi et al. published their work on the asymmetric Rh-catalysed arylation of 4-aryl cyclic ketimines $\mathbf{C 1}$, in which a specialised ligand $\mathbf{L 2}$ was used (Scheme 14). ${ }^{20} \mathrm{~A}$ range of parasubstituted C1 substrates with varying electronic properties were studied, all of which participated in the reaction with various aryl- and alkylboronates efficiently, furnishing the

corresponding 4,4-diaryl (F1) and 4-alkyl-4-aryl sulfamidates in high yields and enafíloselectivities.0.4684 heteroaryl imine substrate was also studied ( $\mathrm{Ar}=2$-furyl) and was found to be viable substrate $(98 \%, 91 \% e e)$.

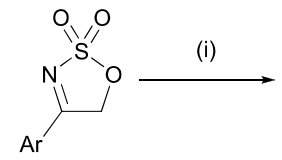

C1

$$
\begin{array}{r}
\text { Reagents: (i) } \mathrm{RB}(\mathrm{OR})_{2} \text { (2 equiv.), }[\mathrm{Rh}(\mathrm{OH})(\mathrm{L} 2)]_{2} \\
t \text {-amyl alcohol:toluene }(1: 1), 60^{\circ} \mathrm{C} .
\end{array}
$$

Scheme 14. The Rh-catalysed nucleophilic arylation reaction of 4-aryl cyclic sulfamidate imines $\mathbf{C 1}$.

The Lin group published their work on a Rh-catalysed asymmetric arylation of 4-alkyl cyclic sulfamidate imines $\mathbf{C 2}$ in 2014, employing their previously developed chiral ligand L3 (Scheme 15). ${ }^{21}$ Various imines $\mathbf{C 2}$ were employed as substrates and while the reaction tolerates varying chain length and steric bulk of the alkyl moiety, the yield of $\mathbf{F} 2$ decreased substantially as either the chain length or the steric bulk of this functionality increased. The reaction was also found to be sensitive to the nature of the boronate reagents, with electron-rich and parasubstituted aryl derivatives being strongly preferred over their electron-deficient and more sterically hindered counterparts.
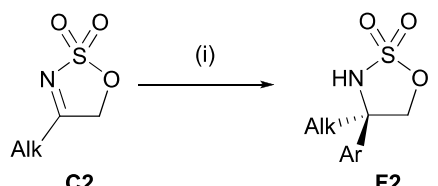

F2

20 examples: $19-99 \%$ up to $99 \%$ ee

Reagents: (i) ArBpin (2 equiv.), $[\mathrm{Rh}(\mathrm{OH})(\mathrm{L} 3)]_{2}$ (1.5 mol\%), $\mathrm{MeOH}$ (4.0 equiv.), dioxane, $80^{\circ} \mathrm{C}$.

Scheme 15. The Rh-catalysed nucleophilic arylation reaction of 4-alkyl cyclic sulfamidate imines C2.

A Rh-catalysed asymmetric nucleophilic addition reaction of 4substituted cyclic sulfamidate imines $\mathbf{C 1}$ and $\mathbf{C 2}$ was reported by Kong and McLaughin et al. in 2015 (Scheme 16).22 Compared to several related $\mathrm{Rh}$-catalysed processes disclosed until this point, the study was the first to successfully employ a commercially available chiral ligand Walphos SL-W001-1. ${ }^{19-21}$ Under the optimised reaction conditions, a wide range of 4-aryl imines c1-the majority of which were electron-deficient-were reacted with various organoboron reagents, furnishing the corresponding products $\mathbf{F} \mathbf{1}$ and $\mathbf{F} \mathbf{3}$ in good to high yields and high enantioselectivities. Several 4-alkyl C2 substrates were also examined $\left(R^{1}=\mathrm{Me}, \mathrm{Et}\right.$, and $\left.c-\mathrm{Pr}\right)$, all of these were found to be viable, delivering the functionalised products $\mathbf{F} 2$ in moderate to good yields and high enantioselectivities. 


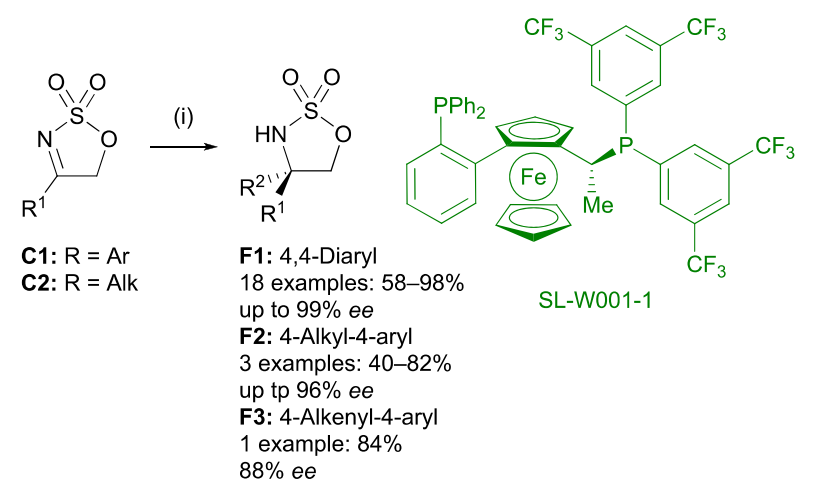

Reagents: (i) $\mathrm{R}^{2} \mathrm{~B}(\mathrm{OH})_{2}(2.0 \text { - } 3.0 \text { equiv.), (acac)Rh(ethylene) })_{2}(5.0 \mathrm{~mol} \%)$, SL-W001-1 (5.5 mol\%), 2-Me-THF, $60^{\circ} \mathrm{C}$.

Scheme 16. The Rh-catalysed nucleophilic addition reaction of sulfamidate imines C1/C2.

The $\mathrm{Xu}$ group disclosed the results of their work on the Rhcatalysed asymmetric arylation reaction of 4-alkyl cyclic imines C2, utilising their in-house developed chiral sulfur-olefin ligand L4 (Scheme 17). ${ }^{23}$ Unlike previous work involving the use of a specialised ligand, the protocol reported by $\mathrm{Xu}$ et al. did not require a pre-prepared $\mathrm{Rh}$ complex. ${ }^{19-21}$ Investigating a similar imine substrate scope to the work of Lin et al., the procedure by $\mathrm{Xu}$ and co-workers seemed to be more tolerant to the chain length of the 4-alkyl moiety, although in both cases, a sharp decline in yield of $\mathbf{F} \mathbf{2}$ was observed when the sterically hindered isopropyl group was present (28\%). A wide range of arylboronic acids were tested, in which electron-rich, meta- and parasubstituted boron reagents were competent substrates. In contrast, heteroaryl-, as well as electron-poor and sterically hindered arylboron substrates performed poorly (12-65\%), albeit furnishing the products in high enantioselectivities (97$99 \%$ ee). These observations were consistent with those reported by Lin and co-workers (Scheme 15). ${ }^{21}$

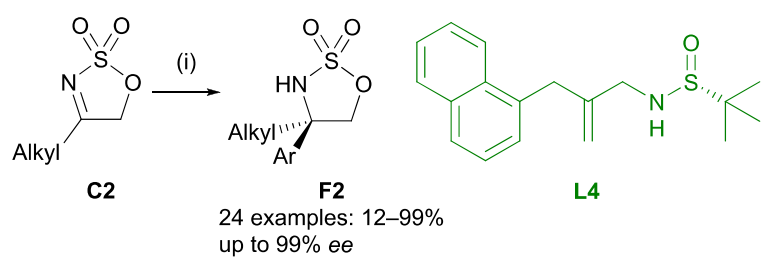

Reagents: (i) $\mathrm{ArB}(\mathrm{OH})_{2}\left(3.0-6.0\right.$ equiv.), $\left[\mathrm{Rh}(\mathrm{Coe})_{2} \mathrm{Cl}\right]_{2}(1.5 \mathrm{~mol} \%)$, L4 (3.3 mol\%), KF (1.0 equiv.), toluene, $80^{\circ} \mathrm{C}$

Scheme 17. The Rh-catalysed nucleophilic addition reaction of 4-alkyl cyclic sulfamidate imine $\mathbf{C 2}$.

In a subsequent study, the Xu group published their work on a Rh-catalysed asymmetric site-selective addition of aryl boronic acid to $\beta$-substituted 4-vinyl cyclic sulfamidate imines C9, employing two specialised ligands L4 and L5 (Scheme 18)..$^{24}$ When chiral ligand $\mathbf{L} 4$ was employed along with potassium fluoride additive, a range of imines $\mathbf{C 9}$ underwent selective 1,2addition reaction with several arylboronic acids to furnish the 4alkenyl-4-aryl sulfamidates $\mathbf{F 3}$ in fair to high yields and high enantioselectivities. Consistent with previous observations, the electron-rich $p$-methoxyphenylboronic acid gave, the highest yield $(86 \%)$, while the yields obtained withothelophengborofife acids were low to moderate (35-63\%). ${ }^{23}$

In contrast, when chiral ligand $\mathbf{L 5}$ was employed with a potassium hydroxide additive, $\beta$-phenyl imines $C 9(R=$ aryl) efficiently underwent selective 1,4-addition with various arylboronic acids, furnishing the corresponding $\beta$-gem-diaryl products $\mathbf{G}$ in good to high yields and high enantioselectivities. Two $\beta$-alkyl C9 substrates were also tested ( $R=M e, c-H e x)$, both were found to be competent substrates, delivering the desired products in high yields and enantioselectivities (76-99\%, 93$98 \%$ ee).
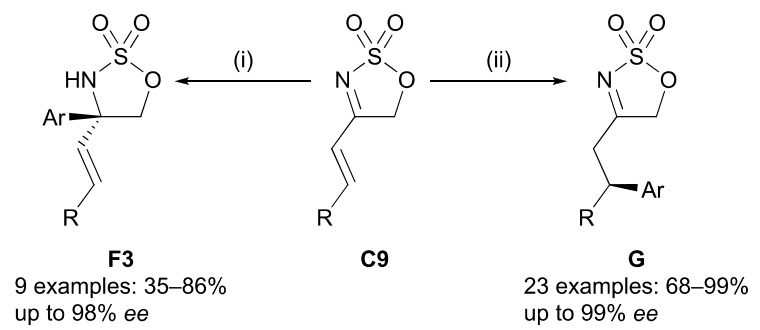

Reagents: (i) $\mathrm{ArB}(\mathrm{OH})_{2}$ (2.0 equiv.), $\left[\mathrm{Rh}(\mathrm{Coe}){ }_{2} \mathrm{Cl}\right]_{2}(2.5 \mathrm{~mol} \%)$, L4 (5.0 mol\%), KF (1.0 equiv.), toluene, $80^{\circ} \mathrm{C}$.

(ii) $\operatorname{ArB}(\mathrm{OH})_{2}\left(2.0\right.$ equiv.), $\left[\mathrm{Rh}(\mathrm{coe})_{2} \mathrm{Cl}\right]_{2}(2.5 \mathrm{~mol} \%)$, L5 (5.0 mol\%), $\mathrm{KOH}$ ( 0.5 equiv.), toluene, rt.

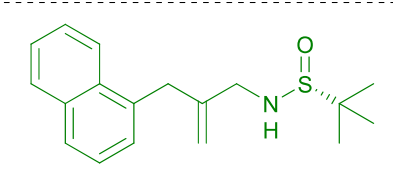

L4

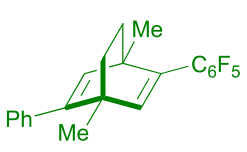

L5
Scheme 18. The site-selective Rh-catalysed nucleophilic addition reaction of 4-vinyl cyclic sulfamidate imines $\mathbf{c}$.

A Pd-catalysed asymmetric arylation reaction of 4-alkyl cyclic sulfamidate imines C2 was reported by Morris et al. in 2018 (Scheme 19). ${ }^{25}$ Many imines $\mathbf{C 2}$ with varying alkyl chain lengths were investigated, all of these were found to be good substrates, furnishing the corresponding products $\mathbf{F} 2$ in good to high yields and enantioselectivities. It was noted that the bulkier chiral ligand ( $R=$ adamantyl) performed well with imines C2 with smaller 4-alkyl substituents, whereas imines bearing a sterically hindered alkyl moiety (Alk $=i$-Pr, $c$-Hex, $c$-Pent, $i$-Bu) were found to be more compatible with the less bulky $t$-Bu PHOX ligand. A wide range of arylboronic acids with diverse electronic and steric properties were investigated, all were found to furnish the desired products in good to high yields in high enantioselectivities. Arylboronic acids bearing orthosubstituents and electron-poor arylboronic acids were competent substrates, which are distinct advantages over the procedures reported previously by the Lin (Scheme 15) and Xu groups (Schemes 17 and 18). ${ }^{21,23,24}$ 

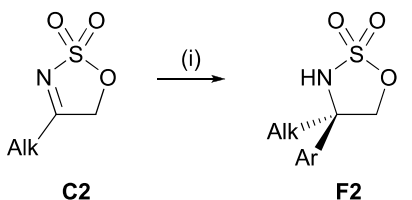

F2
17 examples: $77-98 \%$
up to $99 \%$ ee

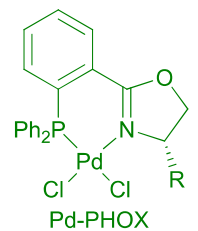

( $\mathrm{R}=$ adamantyl, $t$-Bu)

Reagents: (i) $\mathrm{ArB}(\mathrm{OH})_{2}$ (2.0 equiv.), $\mathrm{Pd}-\mathrm{PHOX}(5 \mathrm{~mol} \%)$, $\mathrm{AgSbF}_{6}(10 \mathrm{~mol} \%), \mathrm{MgO}\left(1.0\right.$ equiv.), $\mathrm{DCB}, 70^{\circ} \mathrm{C}$.

Scheme 19. The Pd-catalysed arylation reaction of 4-alkyl cyclic sulfamidate imines C2.

In 2014, the Nishimura group reported an Ir-catalysed annulation of aromatic imines via direct $\mathrm{C}-\mathrm{H}$ activation (Scheme 20). ${ }^{26}$ With a set of reaction conditions optimised for acyclic aldimines in hand, the authors extended their scope to several acyclic and cyclic imines, among these was 4-phenyl cyclic imine 7. Similar to the observations reported by Lam et al., cyclic sulfamidate imine $\mathbf{7}$ proved to be a challenging substrate, requiring higher catalyst loading as well as significantly longer reaction time. ${ }^{19}$ Moreover, both the starting material $\mathbf{7}$ and the corresponding racemic product $\mathbf{1 7}$ were found to be unstable under the original basic reaction condition, therefore, further adjustments had to be made to avoid the decomposition of these species. Nevertheless, product $\mathbf{1 7}$ was obtained as a single diastereomer in high yield. The stereochemical outcome of this annulation process was addressed in the catalytic cycle proposed by the authors, in which the aryliridium(I) species Int$\mathbf{1}$ was attacked by the diene to form Int-2 in a diastereoselective manner (Scheme 20). Int-2 then can undergo reductive elimination followed by protodemetallation to furnish product 17 and regenerate the active $\operatorname{Ir}(I)$ catalyst.

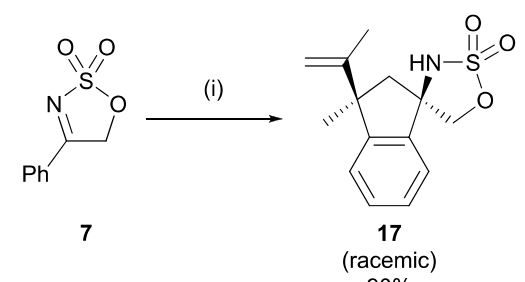

$90 \%$

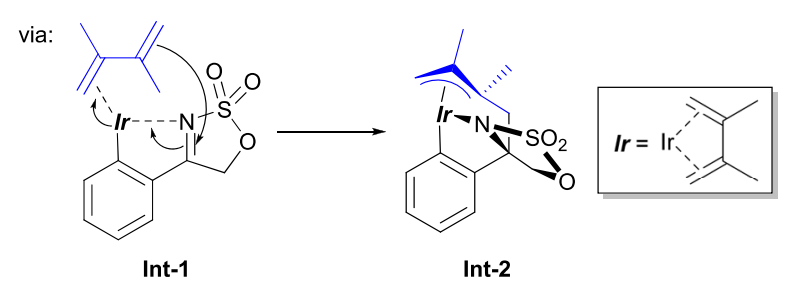

Reagents: (i) 2,3-Dimethylbutadiene (1.5 equiv.), [ $\left[\mathrm{rCl}(\mathrm{coe})_{2}\right]_{2}(5.0 \mathrm{~mol} \%)$, $\mathrm{AcOH}(15.0 \mathrm{~mol} \%), \mathrm{KHCO}_{3}(10 \mathrm{~mol} \%)$, toluene, $80^{\circ} \mathrm{C}$

Scheme 20. The Ir-catalysed annulation reaction of 4-phenyl cyclic sulfamidate imine $\mathbf{7}$.

\subsection{Reactions of cyclic sulfamidate imines with ylides}

The activated double bond of cyclic sulfamidate imines can react with different ylides to form valuable fused heterocyclic scaffolds, as demonstrated in the works of the Tang and the Laha groups. ${ }^{27,28}$

In 2010, Tang et al. reported their work on a diasteregselective two-step one-pot synthesis of racemic cis-vinylažladinesg from 4-aryl imines $\mathbf{C 1}$ using sulfur ylide $\mathbf{H}$ followed by isomerisation by $\mathrm{Pd}\left(\mathrm{PPh}_{3}\right)_{4}$ catalyst (Scheme 21$) .{ }^{27}$ Imines $\mathrm{C} 1$ with varying electronic and steric properties were examined, all of which reacted efficiently to deliver the corresponding products $J$ in good to high yields, and high diastereoselectivities. Sulfur ylides $\mathbf{H}$ bearing functional groups such as carboxyl ester and trimethylsilyl were also tested, and both gave the desired products in moderate yields (64-65\%) with very high diastereoselectivities (cis/trans 99:1). Though the exact mechanism was unclear at the point of disclosure, it was proposed that treatment of the mixture of cis/trans aziridines with $\mathrm{Pd}\left(\mathrm{PPh}_{3}\right)_{4}$ resulted in the formation of two corresponding $\pi$-allylpalladium complexes. Rapid equilibration between these two palladium complexes, followed by reformation of the aziridine allowed the more thermodynamically stable cis-isomer to be formed preferentially.

$$
\begin{aligned}
& \text { (ii) } \mathrm{R}=\mathrm{Ph}, \mathrm{CO}_{2} \mathrm{Me}, \mathrm{TMS} \\
& \text { (racemic) } \\
& \begin{array}{l}
\text { 8 examples: } 52-86 \% \\
\text { up to }>99: 1 \mathrm{dr}
\end{array}
\end{aligned}
$$

Reagents: (i) $\mathbf{H}$ (1.2 equiv.), $t$-BuOK (1.2 equiv.), THF, $0{ }^{\circ} \mathrm{C}$. (ii) $\mathrm{Pd}\left(\mathrm{PPh}_{3}\right)_{4}(10 \mathrm{~mol} \%)$, THF, $0{ }^{\circ} \mathrm{C}$.

Scheme 21. The aziridination reaction of 4-aryl cyclic sulfamidate imines $\mathbf{C 1}$.

A 1,3-dipolar cycloaddition of $\mathrm{N}$-sulfonyl imines was reported by the Laha group in 2017, utilising azomethine ylides derived from precursors K (Scheme 22). ${ }^{28}$ In this work, only the 4-phenyl cyclic sulfamidate imine $\mathbf{7}$ was investigated, which was reacted with several azomethine ylides, generated in situ from the corresponding precursors $\mathrm{K}\left(\mathrm{R}=\mathrm{Bn}, 4-\mathrm{Cl}-\mathrm{Bn}, \mathrm{CH}_{2} \mathrm{Bn}\right)$. Overall, the desired racemic products $\mathbf{M}$ were obtained in poor to moderate yields. The significantly poorer performance of $\mathbf{7}$ compared to other $\mathrm{N}$-sulfonyl aldimines was attributed to the poorer reactivity of ketimines compared to aldimines.

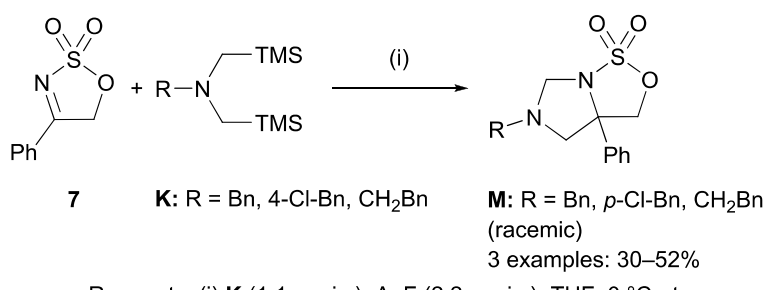

Reagents: (i) $\mathbf{K}$ (1.1 equiv.), $\mathrm{AgF}$ (2.2 equiv.), THF, $0{ }^{\circ} \mathrm{C}-\mathrm{rt}$.

Scheme 22. The 1,3-dipolar cycloaddition reaction of imine $\mathbf{7}$ with azomethine ylides $\mathbf{K}$. 


\section{C5 functionalisation of cyclic sulfamidate imines}

In comparison to the amount of work utilising oxathiazoles as imines, the reactivity of the acidic protons-by virtue of the adjacent imine and sulfamidate moieties - at the $\mathrm{C} 5$ position of this reactive sulfamidate imine platform had received much less attention.

In 2013, the Samanta group reported a novel proline-catalysed diastereoselective synthesis of Z-5-alkylidene cyclic sulfamidate imines $\mathbf{N}$ (Scheme 23a). ${ }^{29}$ The study employed various 4-aryl imines C1 bearing a range of substituents with different substitution patterns on the aryl moiety, as well as 4-heteroaryl imines. All of these imines were competent substrates, undergoing the transformation via Int-3 to exclusively furnish the desired $\mathbf{Z}-5$-akylidene $\mathbf{N}$ products in high yields. When an alkyl imine 14 was reacted with benzaldehyde and $p$ tolualdehyde under the reaction conditions (Scheme 23b), condensation occurred at both the 5-postion and the 4-methyl group, delivering the corresponding products $18 \mathbf{a}$ and $\mathbf{1 8}$ b in high yields.

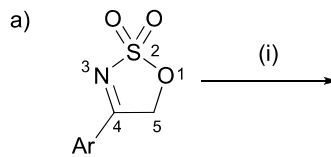

C1

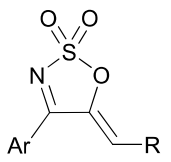

27 examples: $55-97 \%$ $100 \%$ (Z)-isomer

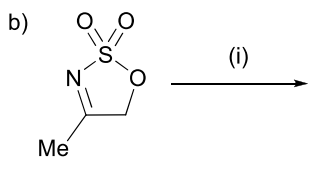

14

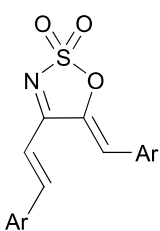

18a: $\mathrm{Ar}=\mathrm{Ph}(87 \%)$

18b: $\mathrm{Ar}=4-\mathrm{Me}-\mathrm{Ph}(83 \%)$
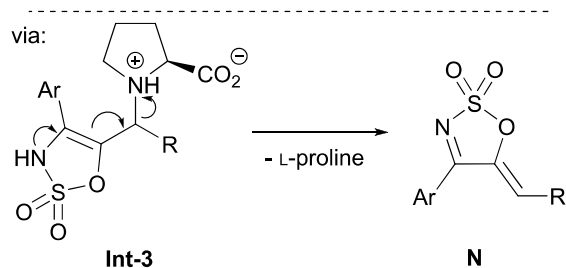

$\mathbf{N}$

Reagents: (i) RCHO (1.1 equiv.), L-Proline (10 mol\%), DMF, rt.

Scheme 23. The proline-catalysed synthesis of Z-5-alkylidene cyclic sulfamidate imines N.

A wide range of aryl aldehydes with diverse electronic and steric properties were used, most of these were found to be high yielding. Electron-deficient aryl aldehydes $\left(\mathrm{R}=3-\mathrm{NO}_{2} \mathrm{C}_{6} \mathrm{H}_{4}\right.$ and 4- $\left.\mathrm{CNC}_{6} \mathrm{H}_{4}\right)$ were viable substrates but delivered the corresponding products $\mathbf{N}$ in only moderate yields ( 55 and $65 \%$, respectively). A few alkyl aldehydes ( $\mathrm{R}=\mathrm{Et}, n-\mathrm{Pr}, n-\mathrm{Bu}$, $\left.(\mathrm{MeO})_{2} \mathrm{Me}\right)$ were tested and were well tolerated. $\alpha, \beta-$ Unsaturated aldehydes were successfully employed to furnish the major 1,4-adducts in good diastereoselectivities (up to, $4: 1$ $d r$ ), albeit in moderate yields (59-63\%). DOI: 10.1039/D0OBO1568G Next, the Samanta group reported a sequential one-pot threecomponent reaction of 4 -aryl imines $\mathbf{C 1},(E)-\alpha, \beta$-unsaturated aldehydes, and formaldehyde, to afford the functionalised spiro-sulfamidate imines $\mathbf{O}$ after oxidation of the formed spiro$\delta$-lactol intermediate with PCC (Scheme 24). ${ }^{30}$ Various imines C1 bearing aryl groups with diverse electronic and steric properties were investigated, all of which reacted smoothly to afford the desired products $\mathbf{O}$ in good to high yields, with moderate to good diastereoselectivities. According to the authors, the stereochemical outcome of the reaction was mainly determined in the condensation between Int-4 with formaldehyde (step (ii), Scheme 24), where up to four possible chair-like transition states TS-1a-d can be adopted. Among these, TS-1a and TS-1 $\mathbf{b}$ were thought to be more favourable as these allow the sterically hindered Ar moiety to adopt an equatorial-like position in the six-membered ring, therefore, favouring the formation of the cis-product.

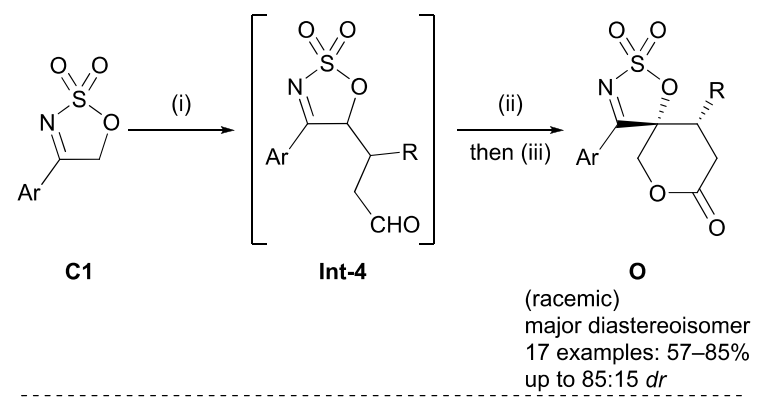

via:

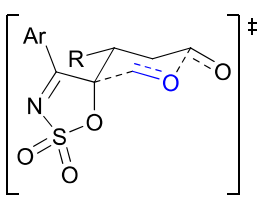

TS-1a

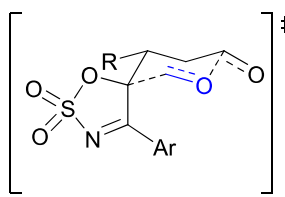

TS-1c

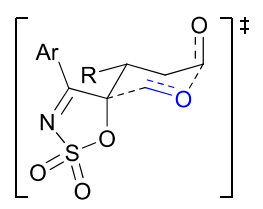

TS-1b

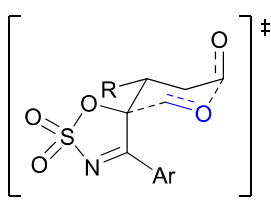

TS-1d
Reagents:(i) (E)-RCH=CHCHO (1.1 equiv.), L-Proline (20 mol\%), $\mathrm{CH}_{2} \mathrm{Cl}_{2}$, rt (ii) $\mathrm{HCHO}$ (1.3 equiv.), $\mathrm{DBU}(30 \mathrm{~mol} \%), \mathrm{CH}_{2} \mathrm{Cl}_{2}$, rt. (iii) PCC ( 3.0 equiv.), $\mathrm{CH}_{2} \mathrm{Cl}_{2}, 40^{\circ} \mathrm{C}$.

Scheme 24. The one-pot three-component diastereoselective synthesis of functionalised spiro-sulfamidate imines $\mathbf{0}$.

Regarding the scope of aldehydes, a range of $(E)$ - $\beta$-arylsubstituted acroleins with varying electronic and steric properties were employed. All were found to be competent substrates, affording the corresponding products $\mathbf{O}$ in good to high yields, with moderate to good diastereoselectivities (70:30-85:15 dr). The reaction was also found to tolerate an $(E)-$ $\beta$-alkyl-substituted acrolein ( $\mathrm{R}=n$-Pr), the reaction of which furnished the desired product in comparable yield $(59 \%)$ but 
slightly lower diastereoselectivity $(69: 31 d r)$ to those observed with aryl derivatives.

In 2015, a highly enantio- and diastereoselective synthesis of highly functionalised cyclic sulfamidate imine-fused transdecalins and cyclohexanes was reported by Vicario et al. (Scheme 25). ${ }^{31}$ Cyclic imine $\mathbf{C 1 0}$ bearing a 1-cyclohexenyl group reacted smoothly with a wide range of $(E)$ - $\beta$-alkyl acroleins to afford the corresponding cyclic sulfamidate imine-fused transdecalins $\mathbf{P}$ in moderate to good yields (57-67\%), and excellent enantioselectivities (95-97\% ee). The chain length of the $\beta$-alkyl groups $R^{3}$ was found to have only minor impact on the outcome of the reaction. When cinnamaldehyde was used $\left(R^{3}=P h\right)$, the reaction was slow, and the product was obtained in significantly diminished yield (30\%), although with high ee (96\%).
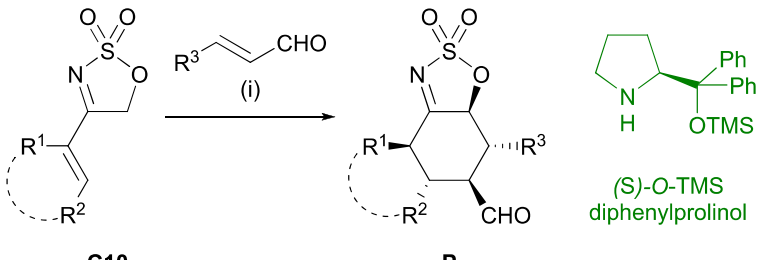

(S)-O-TMS

C10

major diastereoisomer

26 examples: $30-73 \%$

up to $>99 \%$ ee
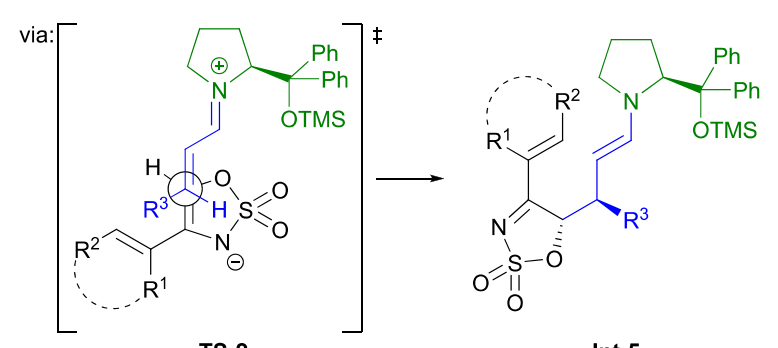

TS-2

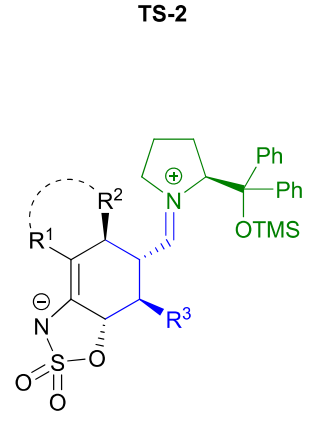

Int-6

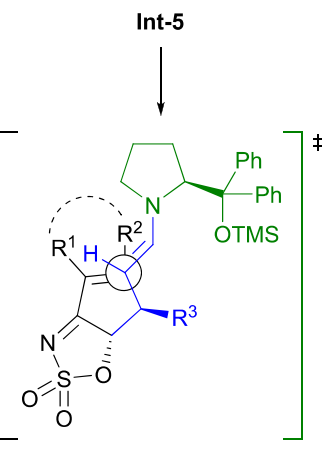

TS-3
Reagents:(i) (E)- $\mathrm{R}^{3} \mathrm{CH}=\mathrm{CHCHO}$ (1.1 equiv.), $\mathrm{DABCO}(20 \mathrm{~mol} \%)$, (S)-O-TMS diphenylprolinol (20 mol\%), $\mathrm{CHCl}_{3},-30^{\circ} \mathrm{C} / \mathrm{rt}$.

Scheme 25. The enantio- and diastereoselective synthesis of cyclic sulfamidate iminefused trans-decalins and cyclohexanes $\mathbf{P}$.

In sharp contrast, substituted acyclic 4-vinyl imines C10 were found to react efficiently with a range of $(E)$ - $\beta$-aryl acroleins with various electronic properties, furnishing the corresponding functionalised cyclohexanes $\mathbf{P}$ in moderate to good yields (50$73 \%)$, and in excellent enantioselectivities (94-99\% ee). The (E)$\beta$-alkyl acrolein crotonaldehyde $\left(R^{3}=M e\right)$ seemed to be poorly compatible, with the desired product obtained in poor yleld (36\%) and slightly diminished enantioseleetivity $991 \%$ ed $1568 \mathrm{G}$ To address the stereochemical outcome of the reaction, the authors proposed a mechanistic pathway that involves two consecutive Michael additions (Scheme 25). The first Michael addition proceeded via TS-2 between the sulfamidate imine nucleophile and the acrolein-derived iminium ion, generating enamine Int-5 with two new stereocenters. Enamine Int-5 then can undergo an intramolecular Michael addition via TS-3 to furnish Int-6 with two additional stereocenters. Lastly, hydrolysis of Int-6 followed by tautomerisation will furnish the desired product and while also forming the final stereocenter, the configuration of which is presumably under thermodynamic control.

In 2018, Vicario and co-workers reported a diastereoselective synthesis of bicyclo[3.1.0]hexanes via an organocatalysedtransannular approach (Scheme 26). ${ }^{32}$ The authors first investigated the base-promoted transannulation reaction of cyclic sulfamidate imine-fused cyclohexanes $\mathbf{P}$-prepared via the previously disclosed procedure-by treatment with $\mathrm{Ph}_{2} \mathrm{CHNH}_{2}$, followed by $1 \mathrm{M} \mathrm{HCl}$ (Scheme 26a). ${ }^{31}$ With $\mathrm{R}^{1}=\mathrm{Me}$, the reaction tolerated various aromatic groups at $R^{2}$, furnishing the corresponding bicyclo[3.1.0]hexanes products $\mathbf{Q}$ in good to high yields and good diastereoselectivities-in which substrates with electron-deficient aryl moieties afforded lower yields compared to those with electron-rich counterparts. Replacing the methyl group with a phenyl group at $R^{1}$ of the cyclohexanefused imine $\mathbf{P}$ resulted in a drastic decline in yields of $\mathbf{Q}(80 \%$ to $50 \%$ with $\mathrm{R}^{2}=\mathrm{Ph}$ ), while the reaction failed to deliver the corresponding bicyclic products when either an ethyl or isopropyl group was placed at $\mathrm{R}^{1}$. To rationalise the stereochemical outcome, the reaction was proposed to have proceeded via enamine Int-7 to give Int-8. Hydrolysis of this species would result in the formation of the bicyclic product $\mathbf{Q}$. The reversal in configuration of the methyl group adjacent to the imine/ketone moiety was presumed to be the result of a thermodynamically driven epimerisation that occurred independently either at the imine precursor or at the ketone product.

The authors next investigated a direct, one-pot approach from vinyl sulfamidate imine $\mathbf{C 1 0}$ via modifying the reaction conditions previously disclosed (Scheme 26b).$^{31}$ Under the new set of reaction conditions, various imines C10-bearing either a 1-cyclohexenyl or an acyclic alkenyl moiety-reacted efficiently with a range of $\beta$-arylacroleins, furnishing the desired products $\mathbf{Q}^{\prime}$ as single diastereoisomers in acceptable yields (30-55\%) and high ee (86-98\%). Attempts to incorporate crotonaldehyde $\left(\mathrm{R}^{3}\right.$ $=\mathrm{Me}$ ) were unsuccessful, and only decomposition of starting materials was observed. Addressing the formation of diastereoisomer $\mathbf{Q}^{\prime}$ in the one-pot procedure instead of its $C 2$ epimer $\mathbf{Q}$, the authors proposed that while Int- $\mathbf{6}$ is favoured at low temperature-the hydrolysis of which would furnish product $\mathbf{P}$, as shown in their previous work (Scheme 25) - Int-9 is favoured when the reaction is operated at elevated temperature. Int-9 then can proceed via a pathway akin to that of Int-7 to furnish the observed product $\mathbf{Q}^{\prime}$. 
a)

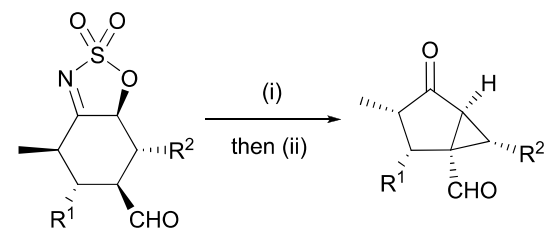

Q: $\mathbf{R}^{1}=\mathrm{Me}, \mathrm{Ph} ; \mathrm{R}^{2}=\mathrm{Ar}$ major diastereoisomer 9 examples: $51-80 \%$ up to $87: 13 d r$

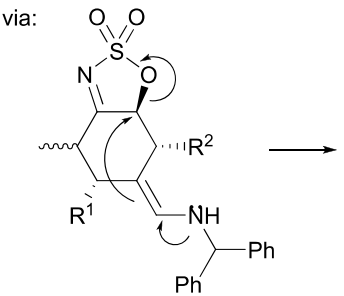

Int-7

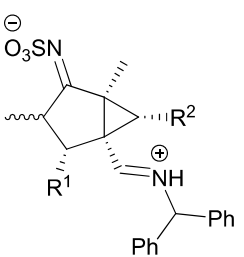

Int-8 b)<smiles>O=[R]1(=O)N=C(C2=CCCCCC2)CO1</smiles>

C10: $\mathrm{R}^{1}=\mathrm{H}, \mathrm{Me}$ $\mathrm{R}^{2}=\mathrm{Me}, \mathrm{Et}, \mathrm{Ph} ;$ $\mathrm{R}^{1}=\mathrm{R}^{2}=\left(\mathrm{CH}_{2}\right)_{4}$ (iii)<smiles>[R]C1C(=O)[C@@H]2[C@H]([R])[C@]2(CO)C1[R]</smiles>

$Q^{\prime}: \mathrm{R}^{1}=\mathrm{H}, \mathrm{Me}$ $\mathrm{R}^{2}=\mathrm{Me}, \mathrm{Et}, \mathrm{Ph}$; $\mathrm{R}^{1}=\mathrm{R}^{2}=\left(\mathrm{CH}_{2}\right)_{4}$ single diastereoisomer 22 examples: $30-55 \%$ up to $98 \%$ ee

via:

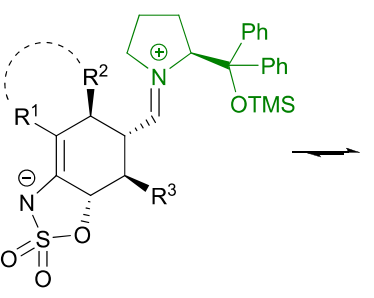

Int-6

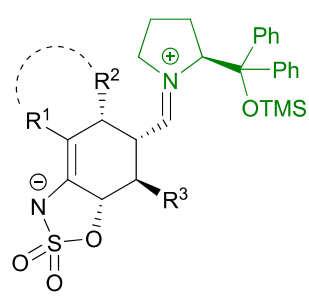

Int-9
Reagents:(i) $\mathrm{Ph}_{2} \mathrm{CHNH}_{2}$ (1.0 equiv.), DCE, $75^{\circ} \mathrm{C}$. (ii) $1 \mathrm{M} \mathrm{HCl}$

(iii) (E)- $\mathrm{R}^{3} \mathrm{CH}=\mathrm{CHCHO}$ (1.5 equiv.), $\mathrm{DABCO}$ (3.0 equiv.),

(S)-O-TMS diphenylprolinol (20 mol\%), DCE, $75^{\circ} \mathrm{C}$.

Scheme 26. The diastereoselective synthesis of bicyclo[3.1.0] hexanes $\mathbf{Q} / \mathbf{Q}^{\prime}$.

The Samanta group over the past few years had published several synthetic pathways utilising the cascade reactions of 4 aryl and 4-heteroaryl cyclic sulfamidate imines with a range of electrophiles $(\mathbf{R})$ to prepare a wide range of highly substituted pyridines (S).

In 2016, Samanta et al. disclosed their work on a domino reaction of 4-aryl imines $\mathbf{C 1}$ with various Morita-Baylis-Hillman (MBH) acetates R1 to prepare 4,6-diaryl- and 6-aryl-4-(E)styrylpicolinates S1 (Scheme 27). ${ }^{33}$ Many imines C1 bearing aryl moieties with varying electronic and steric properties, were used, all of which efficiently furnished thelozipespondiffy picolinate products $\mathbf{S 1}$ in good to high yields. The nature of the substituents as well as the substitution patterns of the aryl moiety of $\mathbf{C 1}$ did not seem to have a significant impact on the efficiency of these reactions.

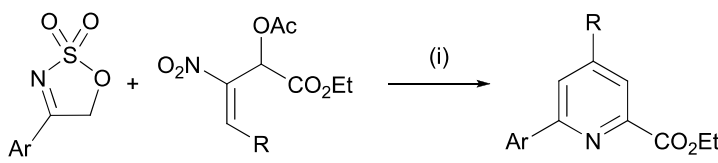

C1 R1: R = Aryl, $(E) \mathrm{CH}=\mathrm{CHAr} \quad$ S1: $\mathrm{R}=\mathrm{Aryl},(E) \mathrm{CH}=\mathrm{CHAr}$ 33 examples: $82-92 \%$

via:
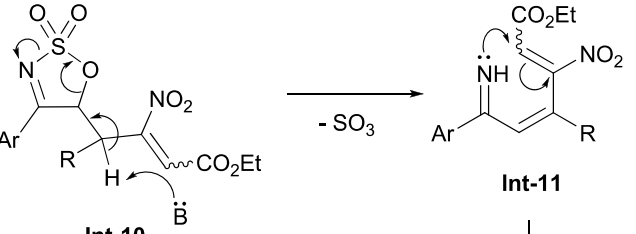

Int-10

Int-11<smiles>[R]c1cc([Al])nc(C(=O)OF)c1</smiles><smiles>[R]C1=CC([Al])=N[C@H]2C[C@H]1[C@H](C(=O)OCC)[C@H]2[N+](=O)[O-]</smiles>

Int-12

Scheme 27. Synthesis of 4,6-disubstituted picolinates S1 via a domino reaction of 4-aryl cyclic sulfamidate imines $\mathbf{C 1}$ with $\mathrm{MBH}$ acetates $\mathbf{R} \mathbf{1}$.

A diverse range of nitroalkene-derived acetates R1 were successfully tested, in which the aryl moieties of these reactants $(\mathrm{R}=$ aryl) were decorated with various substituents with varying electronic and steric properties. While steric hindrance did not seem to have any significant impacts on the outcomes of these reactions, a slight improvement in yields was observed when electron-deficient aryl acetates R1 were employed. Notably, when $\mathrm{MBH}$ acetates of nitrodienes $(\mathrm{R}=$ styryl and 4methoxystyryl) were subjected to the reaction conditions, these substrates reacted exclusively at the $\beta$-position of R1, affording the corresponding 6-aryl-4-(E)-styrylpicolinates in good to high yields (79-85\%).

In the mechanism proposed by the authors, Int-10-formed via the condensation of imine $\mathbf{C 1}$ and $\mathrm{MBH}$ acetate $\mathbf{R 1 - i s}$ converted to Int-11 via deprotonation by DABCO, followed by the loss of $\mathrm{S}_{3}$ molecule. Triene Int-11 can undergo cyclisation to form Int-12, which subsequently rearomatises via the loss of $\mathrm{HNO}_{2}$ to furnish the picolinate $\mathbf{S 1}$.

The following year, the Samanta group published their work on a new synthetic procedure of highly functionalised pyridines via a solvent-free, microwave-assisted domino reaction of cyclic sulfamidate imines $\mathbf{C 1}$ with $\beta, \gamma$-unsaturated $\alpha$-ketocarbonyls (Scheme 28). ${ }^{34} \mathrm{~A}$ wide range of 4-aryl and 4-hetereoaryl imines C1 were efficiently reacted with various electrophiles $\mathbf{R 2}$ to furnish the corresponding 2,4,6-trisubstituted pyridine products S1, S2, and S3 (Scheme 28a). The electronic nature of 
the 4-aryl ring of $\mathbf{C} \mathbf{1}$ had only a minor impact on the performance of the reaction, with electron-deficient substrates found to deliver slightly diminished yields compared to their electron-rich counterparts. 4-Phenyl-5-methyl imine 5 was successfully incorporated as a substrate, the reactions of which with several ester electrophiles $\mathbf{R} 2$ furnished the corresponding tetrasubstituted pyridines $\mathbf{S 4}$ in moderate yields (Scheme $28 \mathrm{~b}$ ).<smiles>O=S1(=O)N=C([Al])C[OH+]1</smiles>

C1<smiles>[R]C=CC(=O)C([R])=O</smiles>

R2: $\mathrm{R}^{1}=\mathrm{Ar},(E) \mathrm{CH}=\mathrm{CHAr}$, phenylethynyl; $R^{2}=\mathrm{OEt}$ 19a: $R^{1}=R^{2}=P h$ 19b: $R^{1}=P h ; R^{2}=$ styryl

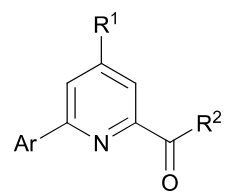

S1: $R^{2}=$ OEt 43 examples: $52-93 \%$ S2: $\mathrm{R}^{1}=\mathrm{R}^{2}=\mathrm{Ph}$ S3: $\mathrm{R}^{1}=\mathrm{Ph} ; \mathrm{R}^{2}=$ styryl 2 examples: $77-78 \%$ 5 examples: $77-86 \%$

b)<smiles>O=C1OS(=O)(=O)N=C1c1ccccc1</smiles>

5<smiles>[R]C=CC(=O)C(=O)OCC</smiles>

$\mathrm{R} 2$ : $\mathrm{Ar},(E) \mathrm{CH}=\mathrm{CHAr}$, phenylethynyl

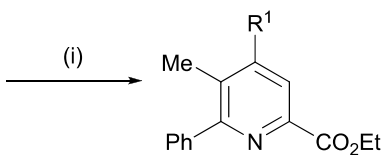

S4: $\mathrm{Ar},(E) \mathrm{CH}=\mathrm{CHAr}$, phenylethynyl 6 examples: $41-58 \%$
Reagents: (i) R2, 19a, or $\mathbf{1 9 b}$ (1.1 equiv.), DABCO (1.0 equiv.), neat, $\mathrm{MW}, 70^{\circ} \mathrm{C}$.

Scheme 28. a) Synthesis of 4,6-disubstituted picolinates $\mathbf{S 1 / S 2 / S 3}$ via domino reaction of 4 -aryl cyclic sulfamidate imines $C 1$ with $\beta, \gamma$-unsaturated $\alpha$-ketocarbonyls R2/19a/19b b) Synthesis of 4,5,6-trisubstituted picolinates $\mathbf{S 4}$ via domino reaction of 5-methyl-4 phenyl cyclic sulfamidate imine $\mathbf{5}$ with $\beta, \gamma$-unsaturated $\alpha$-ketoesters R2 .

The scope of electrophiles was broad, with various $\gamma$-aryl-, $\gamma$ heteroaryl, $\gamma$-styryl, and $\gamma$-phenylethynyl $\beta, \gamma$-unsaturated $\alpha$ ketoesters $\mathbf{R 2}$ being employed as substrates to prepare the corresponding picolinates $\mathbf{S 1}$ and $\mathbf{S 4}$, all of which furnished the desired products in good to high yields (80-93\%). In addition to these, employment of two related bis-carbonyl electrophiles (19a: $R^{1}=R^{2}=P h$ and $19 b: R^{1}=P h, R^{2}=$ styryl) successfully yielded the corresponding disubstituted-pyridinyl ketones $\mathbf{S 2}$ and S3, respectively, in good yields. A single $\gamma$-alkyl ester electrophile $\mathbf{R} \mathbf{2}\left(\mathrm{R}^{1}=i\right.$-Pr, $\left.\mathrm{R}^{2}=\mathrm{OEt}\right)$ was studied, the reaction of which with a $\mathbf{C 1}(\mathrm{Ar}=\mathrm{Ph})$ substrate gave the desired product $\mathbf{S 1}$ in diminished yield (52\%). Overall, the reactivity and the yields reported in this work are in accordance with that observed previously, while the reaction time was significantly reduced. ${ }^{33}$ In the same year, the Samanta group reported a DABCOpromoted domino reaction of 4-aryl cyclic sulfamidate imines C1 with various $\mathrm{MBH}$ acetates $\mathbf{R 3}\left(\mathrm{R}^{1}=\mathrm{CO}_{2} \mathrm{R}, \mathrm{CN}, \mathrm{Ac}\right)$ to prepare 4,6-disubstituted nicotinic acid derivatives $S 5$ (Scheme 29). ${ }^{35} \mathrm{~A}$ wide range of $\mathbf{C 1}$ substrates were reacted against various $\mathrm{MBH}$ acetates $\mathbf{R 3}$ to prepare the corresponding functionalised pyridines in good to high yields. Neither the electronic nor the steric nature of the aryl ring of C1 were found to have a significant impact on the outcomes of these reactions, although electron-deficient 4-aryl C1 derivatives required longer reaction times while and having slightly lowered yields compared to their electron-rich counterparts. Two 4-heteroaryl imines $(\mathrm{Ar}=2$ - furyl and 2-thienyl) were also studied and were found to be competent substrates, furnishing the Dajesireds 9 proauets $68^{\circ}$ slightly lowered yields compared to other 4-aryl substrates.

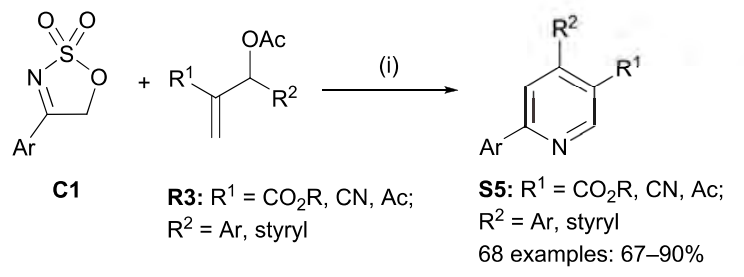

Reagents: (i) R3 (1.1 equiv.), DABCO (1.5 equiv.), 2-Me-THF, $70{ }^{\circ} \mathrm{C}, \mathrm{O}_{2}$.

Scheme 29. The DABCO-promoted synthesis of 4,6-disubstituted nicotinic acid derivatives via domino reaction of 4 -aryl cyclic sulfamidate imines $\mathbf{C 1}$.

Regarding the scope of electrophiles, various acrylate- and acrylonitrile-derived acetates $\mathbf{R} 3\left(\mathrm{R}^{1}=\mathrm{CO}_{2} \mathrm{R}, \mathrm{CN}\right)$ were employed as substrates, all of which reacted efficiently, with electron-rich $\mathrm{MBH}$ substrates exhibiting slightly lower reactivities-requiring significantly longer reaction times. In addition, several acetates $\mathbf{R} 3$ of the methyl vinyl ketone (MVK) type $\left(R^{1}=A c\right)$ were successfully incorporated to the substrate scope, furnishing the corresponding 3-acetyl-4,6diarylpyridines $\mathbf{R} 5$ in good to high yields (73-83\%).

Also in 2017, Samanta and co-workers published their work on a sequential two-step one-pot procedure toward the synthesis of 2,4-diaryl- and 2-aryl-4-styrylpyridines S6 (Scheme 30). ${ }^{36}$ Various imines $\mathbf{C 1}$ with aryl moieties having diverse electronic and steric properties were successfully reacted with a range of acroleins to furnish the corresponding pyridines products $\mathbf{S 6}$ in moderate to high yields, with electron-deficient 4-aryl C1 substrates delivering lowered yields compared to their electron-rich counterparts. Two 4-heteroaryl derivatives $(R=2$ furyl and 2-thienyl) were examined as substrates, both were found to react smoothly, though affording slightly lowered yields (64-76\%) compared to other 4-aryl substrates.<smiles>O=S1(=O)N=C([Al])CO1</smiles>

C1

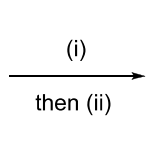

S6: $\mathrm{R}=\mathrm{Aryl},(E) \mathrm{CH}=\mathrm{CHAr}, n-\mathrm{Pr}$ 51 examples: $48-83 \%$

Reagents: (i) (E)-RCH=CHCHO (1.1 equiv.), L-Proline (20 mol\%), PhMe, rt. (ii) DABCO (1.5 equiv.), $40^{\circ} \mathrm{C}$.
Scheme 30. The synthesis of 2,4-disubstituted pyridines S6 via a two-step one-pot reaction of cyclic sulfamidate imines $\mathbf{C 1}$ with $\beta$-substituted acroleins.

Various $\beta$-aryl-and $\beta$-styryl-acroleins were employed to prepare the corresponding 2,4-diaryl- and 2-aryl-4-styrylpyridines S6, respectively. In both cases, electron-deficient derivatives were observed to deliver the corresponding products in slightly higher yields compared to their electron-rich counterparts. Under slightly modified reaction conditions, a single $\beta$ alkylacrolein $(\mathrm{R}=n$ - $\mathrm{Pr}$ ) was successfully employed to furnish the desired 2-aryl-4-alkylpyridine, however, the yield was moderate $(48 \%)$ and the reaction time was significantly longer. 
Recently, the Samanta group disclosed their work on the reaction of 4-aryl- and 4-heteroaryl cyclic sulfamidate imines C1 with various vinyl para-quinone methides ( $\mathrm{p}-\mathrm{QMs}$ ) R4 to furnish a unique para-phenolic substituted pyridine scaffold S7 (Scheme 31). ${ }^{37}$ A range of para-substituted imines C1 with diverse electronic properties were examined, all of which reacted efficiently, furnishing the desired products in good to high yields. Overall, electron-deficient 4-aryl substituted C1 substrates furnished the corresponding products in lower yields compared to their electron-rich counterparts. Two 4-heteroaryl imines C1 ( $\mathrm{Ar}=$ 2-furyl and 2-thienyl) were examined, both were found to be competent substrates, delivering the desired products in comparable yields to the other 4-aryl oxathiazole substrates $(72-76 \%)$.

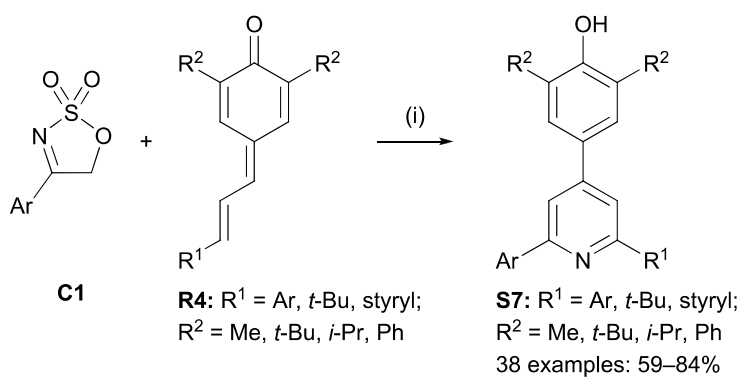

Reagents: (i) R4 (1.2 equiv.), DABCO (1.5 equiv.), 2-Me-THF, $60{ }^{\circ} \mathrm{C}$, air.

Scheme 31. Synthesis of 4-hydroxyaryl-2,6-diarylpyridines $\mathbf{S 7}$ via 1,6-addition of $p$-QMs R4 with cyclic sulfamidate imines $\mathbf{C 1}$.

A diverse range of electrophiles were examined, with various aryl-substituted vinyl $p$-QMs $\mathbf{R 4}$ successfully implemented as substrates, furnishing the desired products in good to high yields overall. The authors remarked that improved yields were observed when electron-poor aryl-substituted R4 were employed compared to electron-rich derivatives. An alkylsubstituted $\mathbf{R 4}$ derivative ( $\mathrm{R}^{1}=t-\mathrm{Bu}$ ) was successfully utilised in this procedure, affording the products in moderate yields (62$64 \%)$, albeit requiring an elevated reaction temperature $\left(85^{\circ} \mathrm{C}\right)$. Styryl-substituted $\mathbf{R 4}\left(\mathbf{R}^{1}=\right.$ styryl) was found to be a competent substrate, reacting smoothly with a few imines $\mathbf{C 1}$ to deliver the corresponding (E)-2,4-diaryl-6-styryl pyridines in moderate yields as single $(E)$-isomer (67-69\%).

A DABCO-catalysed reaction of 4-aryl cyclic sulfamidate imines C1 with a range of racemic isatin-derived carbonates $\mathbf{R 5}$ was reported by Samanta et al. in 2018 (Scheme 32). ${ }^{38}$ Unlike previously reported studies, the reaction between imines C1 and carbonates $\mathbf{R 5}$ did not furnish substituted pyridines, but instead delivered 3,3-disubstituted oxindoles $\mathbf{T}$ in a highly diastereoselective manner. A range of C1 substrates with diverse electronic properties were employed in the reaction with carbonates R5, overall achieving good to high yields and high diastereoselectivities. Consistent with previous observations, electron-deficient aryl imines furnished products with slightly lower yields and diastereoselectivities compared to electron-rich counterparts. ${ }^{34-36} \mathrm{~A}$ single 4-heteroaryl imine (Ar $=2$-furyl) was successfully implemented in this reaction, with the desired product $\mathbf{T}$ being obtained in good yield (76\%) and high diastereoselectivity $(97: 3 \quad d r)$. To explain the stereochemical outcome of the reaction, thelauthors proposed that the reaction may have proceeded via transition state TS-4 (Scheme 32), in which the anion of C1 (blue) overlapped with the ammonium intermediate of $\mathbf{R 5}$ (red) in a manner that maximised $\pi-\pi$ interactions between the two species.

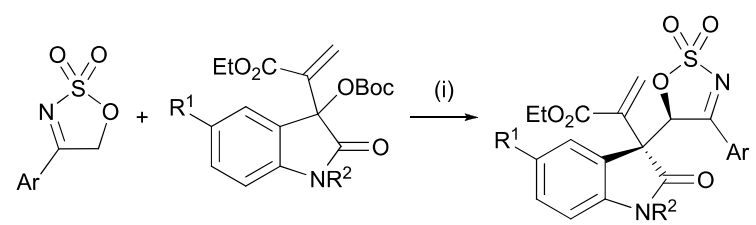

C1
R5: $\mathrm{R}^{1}=\mathrm{Cl}, \mathrm{F}, \mathrm{NO}_{2}$, Me; $\mathrm{R}^{2}=\mathrm{Me}, \mathrm{Et}, \mathrm{Bn}$, allyl, propargyl (racemic)
$\mathrm{T}: \mathrm{R}^{1}=\mathrm{Cl}, \mathrm{F}, \mathrm{NO}_{2}, \mathrm{Me}$; $\mathrm{R}^{2}=\mathrm{Me}, \mathrm{Et}, \mathrm{Bn}$, allyl, propargyl (racemic) 20 examples: $76-90 \%$ up to $96: 4 d r$

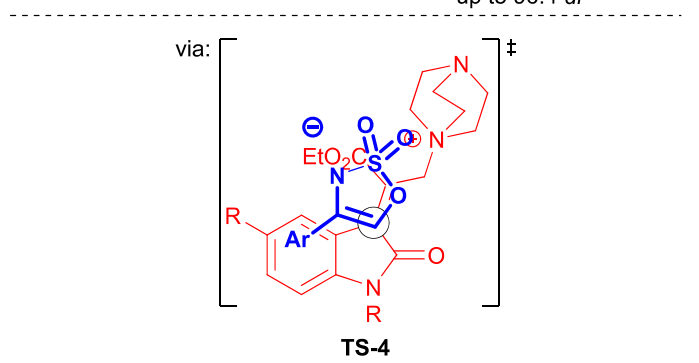

Reagents: (i) R5 (1.2 equiv.), DABCO (5 mol\%), 2-Me-THF, rt.
Scheme 32. The DABCO-catalysed diastereoselective synthesis of 3,3-disubstituted oxindoles.

A wide range of isatin-derived $\mathrm{MBH}$ carbonates $\mathbf{R 5}$ were investigated, with substrates bearing electron-deficient substituents furnishing slightly lowered yields compared to their counterparts with electron-donating substituents. Many carbonates R5 bearing different functionalities on the $\mathrm{N}$ heteroatom were used in the study, all of which were well tolerated.

\section{Applications in synthesis}

In 2012, the H.-K. Lee group applied their previous work on the ATH-DKR procedure to derive a new approach toward the synthesis of norephedrine (NE) 22a and norpseudoephedrine (NPE) 22b (Scheme 33a). ${ }^{6}$ Imine 20a was subjected to the previously described ATH-DKR reaction conditions to furnish the chiral sulfamidate 21a in high yield and enantioselectivity. Recrystallisation of 21a further improved the enantiomeric purity to $>99 \%$ ee. The enantiomerically pure sulfamidate 21 a was then reduced with $\mathrm{LiAlH}_{4}$ to yield the corresponding NE 22a in $72 \%$ yield without any erosion in enantiomeric purity.

The preparation of the NPE derivative 22b from 20a required several additional steps due to the inversion of the stereogenic centre bearing the hydroxy group. To synthesise 22b, enantiomerically pure sulfamidate 21a was first treated with $\mathrm{Boc}_{2} \mathrm{O}$ in the presence of a catalytic amount of DMAP to afford $\mathbf{N}$-Boc-21a in high yield, which was then reacted with benzoic 
acid in the presence of CsF to afford the acyclic product $\mathbf{2 3}$ with inversion of configuration. Compound $\mathbf{2 3}$ was then deprotected to furnish $\mathbf{2 2 b}$ in $\mathbf{7 4 \%}$ yield over two steps. Notably, no erosion of enantiomeric purity occurred throughout the four-step synthesis of $\mathbf{2 2} \mathbf{b}$ from sulfamidate $\mathbf{2 1} \mathbf{a}$.

The enantiomers of both $\mathbf{2 2 a}$ and $\mathbf{2 2} \mathbf{b}$ can be readily accessed via the same procedures starting with imine $\mathbf{2 0 a}$, differing only in the chirality of the Rh catalyst employed in the ATH-DKR step. In addition, H.-K. Lee and co-workers also prepared two sulfamidate analogues $\mathbf{2 1 b}$ and $\mathbf{2 1 c}$ via the ATH-DKR approach (Scheme 33b). Both species were furnished from the corresponding imines $\mathbf{2 0 b}$ and $\mathbf{2 0 c}$, respectively, in high yields and enantioselectivities.

a)<smiles>CC1=NS(=O)(=O)OC1c1ccccc1</smiles>

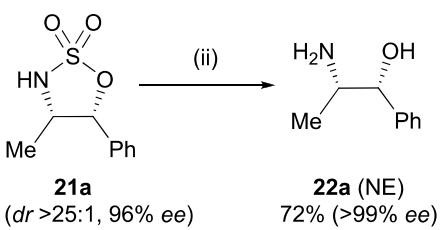

(iii)

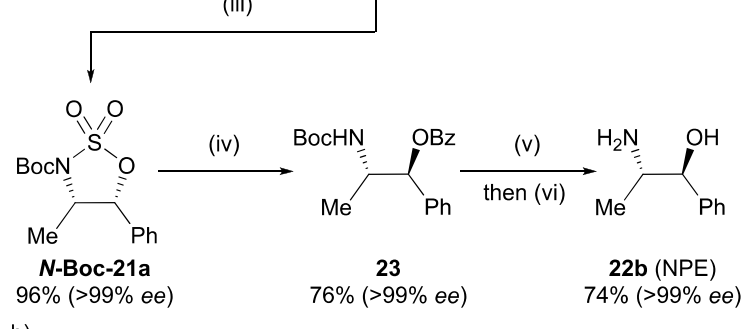

b)

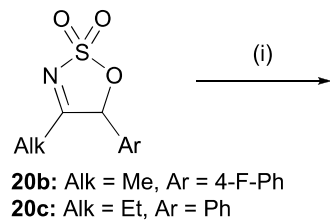

$$
\text { Alk }
$$

21b: Alk $=\mathrm{Me}, \mathrm{Ar}=4-\mathrm{F}-\mathrm{Ph}$

$84 \%(d r>25: 1,93 \%$ ee $)$

21c: $\mathrm{Alk}=\mathrm{Et}, \mathrm{Ar}=\mathrm{Ph}$

$79 \%(d r>25: 1,93 \%$ ee $)$

Reagents: (i) $\operatorname{RhCl}((R, R)-T s D P E N] C C^{*}(0.3 \mathrm{~mol} \%)$ $\mathrm{HCOOH} / \mathrm{Et}_{3} \mathrm{~N}(5: 2)$, EtOAc, rt.

(ii) $\mathrm{LiAlH}_{4}$ (3.0 equiv.), $\mathrm{THF}, 0^{\circ} \mathrm{C}$.

(iii) $\mathrm{Boc}_{2} \mathrm{O}$ (2.0 equiv.), DMAP ( $\left.8 \mathrm{~mol} \%\right), \mathrm{CH}_{2} \mathrm{Cl}_{2}$, rt.

(iv) $\mathrm{CsF}$ (1.4 equiv.), $\mathrm{PhCOOH}$ (1.4 equiv.), DMF, $60^{\circ} \mathrm{C}$ (v) $\mathrm{KCN}$ ( 0.5 equiv.), $\mathrm{MeOH}, 65^{\circ} \mathrm{C}$.

(vi) TFA (5.0 equiv.), $\mathrm{CH}_{2} \mathrm{Cl}_{2}$, rt.

Scheme 33. Synthesis of Norephedrine (NE) and Norpseudophedrine (NPE) via the ATHDKR reaction of cyclic sulfamidate imines.

In 2013, the McLaughin group disclosed their second generation synthesis of chiral piperazinone derivative $\mathbf{2 7 - o n e ~ o f ~ t h e ~ t w o ~}$ main fragments of a clinical candidate for the treatment of migraine headache-employing chiral sulfamidate $\mathbf{2 5}$ as a key synthetic intermediate (Scheme 34 ). ${ }^{8}$ To carry out the key transformation from imine $\mathbf{2 4}$ to sulfamidate $\mathbf{2 5}$, a Pd-catalysed asymmetric hydrogenation procedure akin to that described by Zhou et al. was implemented. ${ }^{5}$ Under this modified reduction procedure, 25 was obtained in high yield and high enantioselectivity. Chiral sulfamidate $\mathbf{2 5}$ was then reacted with cycloleucine in a three-stage one-pot transformation, proceeding via Int-13, to afford piperazinone 26 in good yield without any significant erosion in enahtiomeric Alkylation of $\mathbf{2 6}$ with ethyl bromoacetate followed by an in situ hydrolysis of the ester moiety afforded the desired piperazinone acid $\mathbf{2 7}$ in high yield. The enantiomeric purity of 27 was reported to be $99.7 \%$ after recrystallisation.<smiles>O=S1(=O)CCC(c2cc(F)cc(F)c2)=N1</smiles>

24

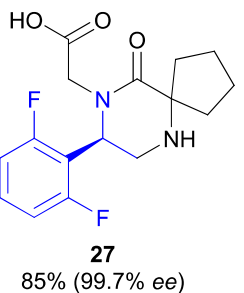

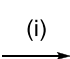<smiles>O=S1(=O)NC(c2cc(F)cc(F)c2)CO1</smiles>

25 $94 \%(97 \%$ ee $)$

(ii)
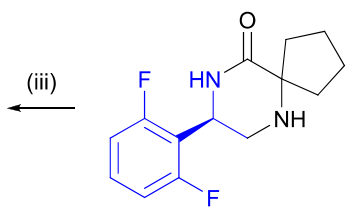
$70 \%(96 \%$ ee $)$

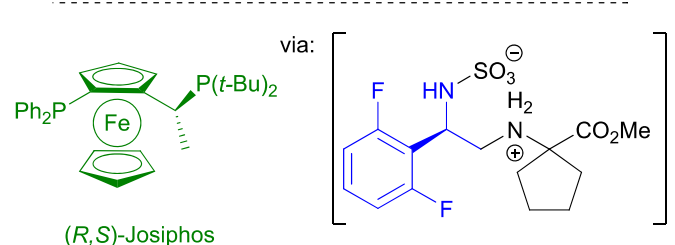

Int-13
Reagents: (i) $\mathrm{Pd}(\mathrm{OAc})_{2}(0.3 \mathrm{~mol} \%)$,

$(R, S)$-Josiphos (0.33 mol\%), $\mathrm{H}_{2}(40 \mathrm{psi}), \mathrm{MeOH}, 40^{\circ} \mathrm{C}$.

(ii) (a) Cycloleucine (1.5 equiv.), sulfolane, $70^{\circ} \mathrm{C}$.

(b) $5 \mathrm{~N} \mathrm{HCl}, 50^{\circ} \mathrm{C}$. (c) $\mathrm{NaOH}$ (pH 8-9), $60^{\circ} \mathrm{C}$.

(iii) (a) Ethyl bromoacetate (1.4 equiv.), NAHMDS (1.3 equiv.), $\mathrm{THF},<10^{\circ} \mathrm{C}$ (b) $\mathrm{LiOH}\left(3.0\right.$ equiv.), $0-20^{\circ} \mathrm{C}$.

Scheme 34. A revised synthesis of a chiral piperazinone acid derivative $\mathbf{2 7}$.

In 2017, Allison and Mani disclosed their work on a revised, gram-scale synthesis of $\mathbf{3 1}$-an oxazine class $\beta$-Secretase 1 (BACE 1) inhibitor-featuring a key sulfamidate 29 intermediate (Scheme 35). ${ }^{39}$ Treatment of racemic imine $\mathbf{2 8}$ precursor with methyl Grignard reagent yielded racemic sulfamidate 29 in good yield. The racemate was then resolved with chiral HPLC to afford enantiomerically pure $\mathbf{2 9}$ in $\mathbf{4 8 \%}$ yield, which was then ring-opened with $\mathrm{LiAlH}_{4}$ to furnish $\mathbf{3 0}$ in near quantitative yield. Amino alcohol $\mathbf{3 0}$ was then subjected to a further six synthetic steps to deliver 31 in an overall 14\% yield over the total elevenstep synthetic procedure from $\mathbf{2 8}$.

In Allison and Mani's work, notably, the Grignard reaction of $\mathbf{2 8}$ was successfully carried out in THF using $\mathrm{MeMgBr}$, whereas in a previous report, no reaction between 3 and $\mathrm{MeMgl}$ was observed at $-78^{\circ} \mathrm{C}$ when THF was employed as solvent (Scheme 11). ${ }^{17}$ In addition, the authors remarked that methyl tert-butyl 
ether (MTBE) might have been superior to THF-agreeing with Chang and Lee's findings-but due to a "strict project timeline", the use of this solvent was not investigated further. ${ }^{17,39}$

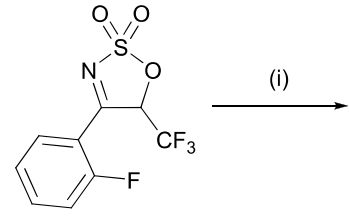

28

Reagents: (i) $\mathrm{MeMgBr}$ (1.4 equiv.), $\mathrm{THF},-67$ to $-10{ }^{\circ} \mathrm{C}$

(ii) Preparative chiral HPLC

(iii) $\mathrm{LiAlH}_{4}$ (1.65 equiv.), THF, $50^{\circ} \mathrm{C}$.

Scheme 35. Synthesis of the oxazine class BACE 1 inhibitor 31

In 2017, Liu and Wan et al. disclosed a novel approach toward the synthesis of various 3-amino and 3-nitro-2,3,6deoxypyranoses-important saccharides found in many biologically active natural products-and their analogues, employing several sugar-derived cyclic sulfamidate imines as key synthetic intermediates (Scheme 36). ${ }^{40}$ In this work, the authors reported the reactivity of the acidic proton at the $C 4$ position of the pyranose ring when the $\mathrm{C} 4$ epimers 32 and $32 \mathrm{a}$ delivered the same 4,5-trans product 33 (along with its C1 epimer as minor product) under basic $(\mathrm{NaOMe} / \mathrm{MeOH})$ reaction conditions (Scheme 36a). Similar results were observed when the enantiomers of $\mathbf{3 2}$ and $\mathbf{3 2 a}$ were subjected to the same reaction conditions. It was rationalised that the 4,5-trans product $\mathbf{3 3}$ (and their corresponding $\mathrm{C} 1$ epimers) were favoured because in this geometry, both substituents at $\mathrm{C} 4$ and $\mathrm{C} 5$ of the pyranose ring can adopt pseudo-equatorial positions, therefore, making these isomers the more thermodynamically stable compared to the 4,5-cis products, none of which were observed.

Imine $\mathbf{3 3}$ and its enantiomer were subsequently reacted with $\mathrm{MeMgBr}$ to furnish the corresponding sulfamidate $\mathbf{3 4}$ and its enantiomer in high yields, and only the 3,4-cis products were obtained. Similar results were reported when imine $\mathbf{3 3}$ and its enantiomer, and two other related imines $\mathbf{3 5}$ and $\mathbf{3 6}$ were reduced with $\mathrm{LiAlH}_{4}$ (Scheme 36b). The reaction of these imines with $\mathrm{LiAlH}_{4}$ all proceeded smoothly, furnishing the corresponding 3-amino sugars $\mathbf{3 7 - 3 8}$ in high yields, and in all cases, only the 3,4-cis products were obtained. The results observed in these experiments suggested that in the reactions

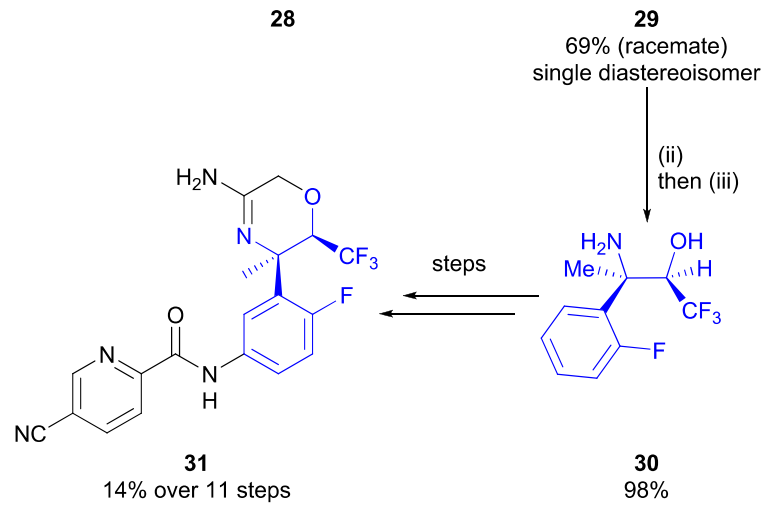

with either Grignard reagent or $\mathrm{LiAlH}_{4}$, the nucleopbiles attack preferentially from the opposite face to the $\mathrm{OSO}_{2}^{3}$ PUPCETEmant? affording exclusively the 3,4-cis products.

a)<smiles>C[C@H]1OC=CC2=NS(=O)(=O)O[C@@H]2[C@H]1O</smiles>

32

$32 a$

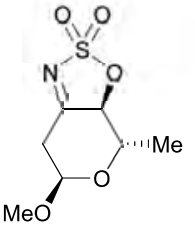

33

$85-94 \%$ up to $7.5: 1 d r$

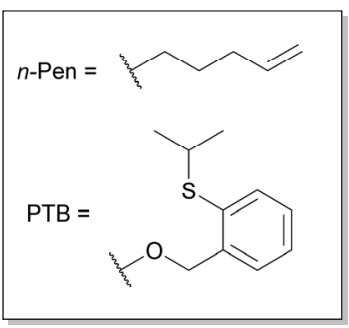

b)

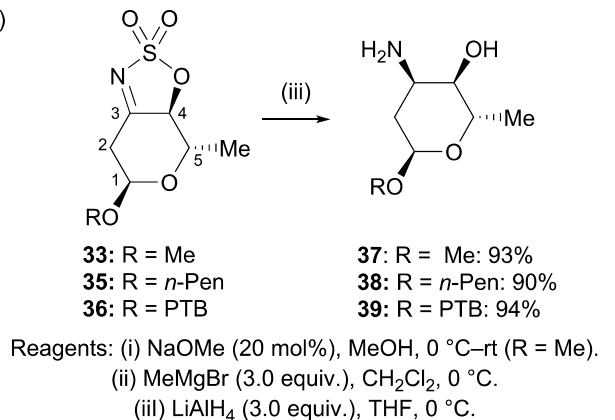

(iil) $\mathrm{LiAlH}_{4}$ (3.0 equiv.), $\mathrm{THF}, 0{ }^{\circ} \mathrm{C}$.

Scheme 36. Reactions of various sugar-derived cyclic sulfamidate imines.

In 2018, Hogan et al. reported the large-scale syntheses of several building blocks that are used to assemble the 15membered macrolide $\mathbf{U}$, one of which is the chiral amide $\mathbf{4 2}$ (Scheme 37). ${ }^{41}$ In this work, two pathways were investigated for the synthesis of $\mathbf{4 2}$, one of which was the ATH-DKR procedure reported by H.-K. Lee et al. ${ }^{10}$ Via this method, sulfamidate $\mathbf{4 1}$ was successfully prepared on a 600-gram scale from the benzoin-derived cyclic sulfamidate imine precursor 40 , using a 0.05 mol\% of the chiral Rh catalyst. Sulfamidate $\mathbf{4 1}$ was taken through several further synthetic steps toward $\mathbf{4 2}$ but eventually was not used to prepare this scaffold. Despite the successful large-scale synthesis of 41, the authors remarked that this ATH-DKR approach was too lengthy and resourceintensive-particularly in solvent usage-and therefore not suitable to be applied as a manufacturing protocol. 


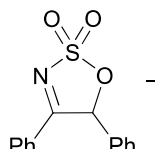

40

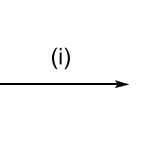

41 $97 \%$ (no ee data)

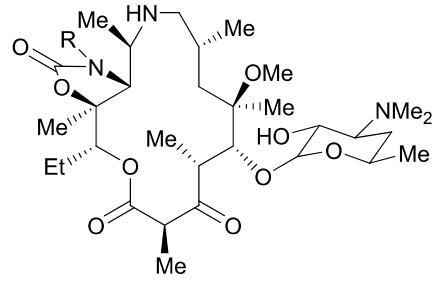

u $\mathrm{Ph}$

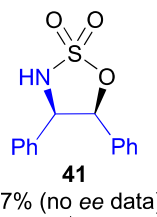

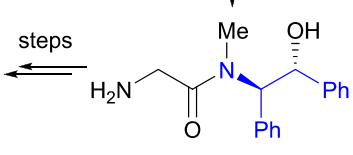

42

Reagents: (i) RhCl[(R,R)-TsDPEN]Cp* $(0.05 \mathrm{~mol} \%), \mathrm{HCOOH} / \mathrm{Et}_{3} \mathrm{~N}, \mathrm{EtOAc}$, rt.

Scheme 37. The use of the ATH-DKR reaction of benzoin-derived cyclic sulfamidate imine $\mathbf{4 0}$ to prepare key building block $\mathbf{4 1}$.

In 2018, Morris and co-workers utilised their newly developed $\mathrm{Pd}$-catalysed asymmetric arylation procedure in their formal synthesis of Verubecestat 46-a $\beta$-secretase inhibitor currently in clinical trials for the treatment of Alzheimer's disease (Scheme 38). ${ }^{25}$ In this procedure, sulfamidate imine 14 was reacted with 2-fluoro-5-bromophenylboronic acid under the optimised reaction conditions, using Pd-AdamantylPHOX catalyst complex (see Scheme 19), to furnish chiral sulfamidate 43 in $92 \%$ and $99 \%$ ee. Sulfamidate $\mathbf{4 3}$ was then reacted with $\mathrm{PhOC}(\mathrm{S}) \mathrm{Cl}$ to form 44, which underwent intramolecular nucleophilic substitution followed by desulfonylation at elevated temperature $\left(60^{\circ} \mathrm{C}\right)$ to yield dihydrothiazole $45(86 \%$, no ee data provided). Further manipulation of $\mathbf{4 5}$ allowed the construction of Verubecestat $\mathbf{4 6}$ in $41 \%$ yield from imine $\mathbf{1 4 .}$

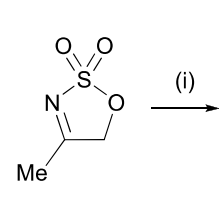

14

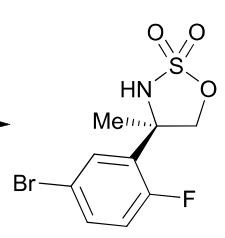

43

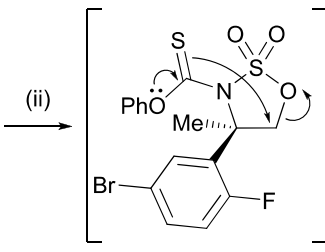

44

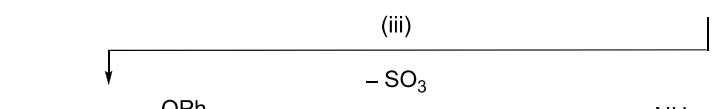<smiles>CN1C(N)=N[C@](C)(c2cc(NC(=O)c3ccc(F)cn3)ccc2F)CS1(=O)=O</smiles>

45 $86 \%$

46 (Verubecestat) $41 \%$ from 14

Reagents: (i) 2-F-5-Br-Ph-B(OH) 2 (2.0 equiv.), Pd-AdamantylPHOX (5 mol\%), $\mathrm{AgSbF}_{6}(10 \mathrm{~mol} \%), \mathrm{MgO}\left(1.0\right.$ equiv.), $\mathrm{DCB}, 70^{\circ} \mathrm{C}$.

(ii) $\mathrm{KOtBu}$ (1.1 equiv.), $\mathrm{PhOC}(\mathrm{S}) \mathrm{Cl}$ (1.1 equiv.), $\mathrm{DMF}$, rt. (iii) $60^{\circ} \mathrm{C}$.

Scheme 38. Synthesis of Verubecestat 46-a BACE 1 inhibitor.

\section{Conclusions}

Vlew Article Online DOI: $10.1039 /$ DOOBO1568G From this review, it is clear that five-membered cyclic sulfamidate imines are useful precursors for the synthesis of novel and valuable structures containing multiple heteroatoms. Numerous studies have exploited the highly electrophilic imine moiety of this stereodefined scaffold to develop various enantioselective and high-yielding reduction and nucleophilic addition protocols. The dynamic kinetic resolution of these imines with $\alpha$-stereocentres under transfer hydrogenation conditions being a particular highlight-allowing the creation of two stereocentres in a single step (Schemes 5-7, 9, 10, 33, and 37). However, in comparison, cycloaddition reactions to the imine are more limited and deserve further attention as they have the potential to provide routes to highly complex and stereodefined targets containing multiple heteroatoms. Future progress in this area likely will involve further developments of enantioselective reactions involving the imine moiety of these cyclic sulfamidate imines with, for example, ylides and 1,3dipoles.

In addition to being a good electrophilic substrate, cyclic sulfamidate imines-by virtue of the highly acidic proton(s) $\alpha$ to the imine functionality-have been efficiently employed as nucleophiles in many cascade procedures to prepare highly functionalised heterocycles such as pyridines (S1-7, Schemes 27-31), imine-fused trans-decalins/cyclohexanes (P, Scheme 25), and bicyclo[3.1.0]hexanes ( $\mathbf{Q}$ and $\mathbf{Q}^{\prime}$, Scheme 26).

Further advancements exploiting the nucleophilic nature of these substrates will broaden their utility in organic synthesis. The potential of 1,2- and 1,4-addition reactions of 5-alkylidene derivatives like $\mathbf{N}$ (Scheme 23), or their participation in cycloaddition reactions, may also be disclosed in future studies.

\section{Conflicts of interest}

There are no conflicts to declare.

\section{Acknowledgements}

The authors acknowledge ARC Discovery project, DP18 263371037 for generous funding of our research in this area.

\section{Notes and references}

1 R. E. Meléndez and W. D. Lubell, Tetrahedron, 2003, 59, 2581-2616.

2 J. F. Bower, J. Rujirawanich and T. Gallagher, Org. Biomol. Chem., 2010, 8, 1505-1519.

3 A. Megia-fernandez, J. Morales-sanfrutos, F. Hernandezmateo and F. Santoyo-Gonzalez, Curr. Org. Chem., 2011, 15, 401-432.

4 R. Baig, M. Nadagouda and R. Varma, Aldrichimica Acta, 2015, 48, 71-80.

5 Y. Q. Wang, C. Bin Yu, D. W. Wang, X. B. Wang and Y. G. Zhou, Org. Lett., 2008, 10, 2071-2074.

6 H.-K. Lee, K. Soyeong and E. B. Choi, J. Org. Chem., 2012, 77, 5454-5460.

7 S. Kang, J. Han, E. S. Lee, E. B. Choi and H. Lee, Org. Lett., 2010, 12, 4184-4187. 
8 M. McLaughlin, K. Belyk, C. Y. Chen, X. Linghu, J. Pan, G. Qian, R. A. Reamer and Y. Xu, Org. Process Res. Dev., 2013, 17, 1052-1060.

9 S. A. Lee, S. H. Kwak and K. I. Lee, Chem. Commun., 2011, 47, 2372-2374.

10 J. Han, S. Kang and H. K. Lee, Chem. Commun., 2011, 47, 4004-4006.

11 Y. Liu, Y. Huang, Z. Yi, G. Liu, X. Q. Dong and X. Zhang, Adv. Synth. Catal., 2019, 361, 1582-1586.

12 Y. Liu, Z. Yi, X. Tan, X. Q. Dong and X. Zhang, iScience, 2019, $19,63-73$.

13 J. A. Kim, Y. J. Seo, S. Kang, J. Han and H. K. Lee, Chem. Commun., 2014, 50, 13706-13709.

14 S. Itsuno, Y. Hashimoto and N. Haraguchi, J. Polym. Sci. Part A Polym. Chem., 2014, 52, 3037-3044.

15 Y. J. Seo, J. A. Kim and H. K. Lee, J. Org. Chem., 2015, 80, 8887-8902.

16 H. R. Kim, R. Achary and H. K. Lee, J. Org. Chem., 2018, 83, 11987-11999.

17 S. Chang and E. E. Lee, Synthesis, 2010, 2361-2366.

18 A. Pitchaiah, M. Kim, I. Hwang and K.-I. Lee, Curr. Org. Synth., 2013, 10, 798-802.

19 H. B. Hepburn, N. Chotsaeng, Y. Luo and H. Lam, Angew. Chemie. Int. Ed., 2012, 51, 8309-8313.

20 T. Nishimura, Y. Ebe, H. Fujimoto and T. Hayashi, Chem. Commun., 2013, 49, 5504-5506.

21 Y. J. Chen, Y. H. Chen, C. G. Feng and G. Q. Lin, Org. Lett., 2014, 16, 3400-3403.

22 J. Kong, M. McLaughlin, K. Belyk and R. Mondschein, Org. Lett., 2015, 17, 5520-5523.

23 M.-Q. Liu, T. Jiang, W.-W. Chen and M.-H. Xu, Org. Chem. Front., 2017, 4, 2159-2162.

24 C. Y. Wu, Y. F. Zhang and M. H. Xu, Org. Lett., 2018, 20, 17891793.

25 W. Chen, D. Meng, B. N'Zemba and W. J. Morris, Org. Lett., 2018, 20, 1265-1268.

26 Y. Ebe, M. Hatano and T. Nishimura, Adv. Synth. Catal., 2015, 357, 1425-1436.

27 B. H. Zhu, J. C. Zheng, C. Bin Yu, X. L. Sun, Y. G. Zhou, Q. Shen and Y. Tang, Org. Lett., 2010, 12, 504-507.

28 J. K. Laha, K. P. Jethava, K. S. S. Tummalapalli and S. Sharma, Eur. J. Org. Chem., 2017, 4617-4624.

29 D. Majee, A. Srivastava, S. M. Mobin and S. Samanta, RSC Adv., 2013, 3, 11502-11506.

30 D. Majee, S. Biswas, S. M. Mobin and S. Samanta, Tetrahedron Lett., 2014, 55, 4553-4558.

31 I. Riaño, U. Uria, L. Carrillo, E. Reyes and J. L. Vicario, Org. Chem. Front., 2015, 2, 206-210.

32 I. Riano, U. Uria, E. Reyes, L. Carrillo and J. L. Vicario, J. Org. Chem., 2018, 83, 4180-4189.

33 D. Majee, S. Biswas, S. M. Mobin and S. Samanta, J. Org. Chem., 2016, 81, 4378-4385.

34 S. Biswas, D. Majee, S. Guin and S. Samanta, J. Org. Chem., 2017, 82, 10928-10938.

35 D. Majee, S. Biswas, S. M. Mobin and S. Samanta, Org. Biomol. Chem., 2017, 15, 3286-3297.

36 D. Majee, S. Guin, S. Biswas and S. Samanta, ChemistrySelect, 2017, 2, 3423-3427.

37 S. Guin, S. K. Gudimella and S. Samanta, Org. Biomol. Chem., 2020, 18, 1337-1342.

38 S. K. Arupula, S. Guin, A. Yadav, S. M. Mobin and S. Samanta, J. Org. Chem., 2018, 83, 2660-2675.

39 B. D. Allison and N. S. Mani, ACS Omega, 2017, 2, 397-408.

40 J. Zeng, G. Sun, W. Yao, Y. Zhu, R. Wang, L. Cai, K. Liu, Q. Zhang, X. W. Liu and Q. Wan, Angew. Chemie. Int. Ed., 2017, 56, 5227-5231.
41 P. C. Hogan, C. L. Chen, K. M. Mulvihill, J. F. Lawrence, E. Moorhead, J. Rickmeier and A. G. Myersid.Antibioter 2018, 71, 318-325. 


\section{Authors}

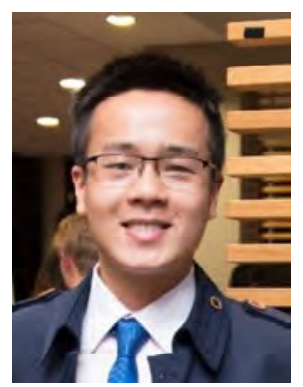

Quoc Hoang Pham received his Bachelor of Science (Honours) degree in chemistry from the University of Wollongong (Australia) in 2018, where he is currently studying towards a Ph.D. degree in organic synthesis under the supervision of Professor Stephen Pyne and Associate Professor Christopher Hyland. His research is focused on the synthesis of highly functionalised heterocycles and their application in organic synthesis.

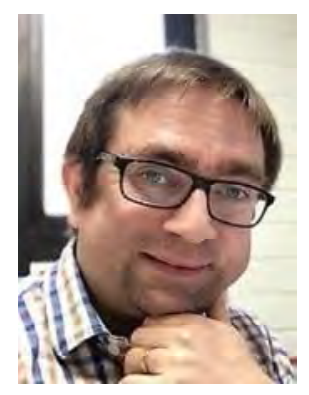

Christopher J T Hyland obtained his undergraduate degree and Ph.D. (2004) from Imperial College, London under the supervision of Professor Donald Craig. After carrying out postdoctoral research with Professor Louis Hegedus at Colorado State University he started his independent career at California State University, Fullerton. Following a Lectureship at the University of Tasmania he moved to the University of Wollongong where he is an Associate Professor. His independent research interests encompass transition-metal catalysts and medicinal organometallic chemistry.

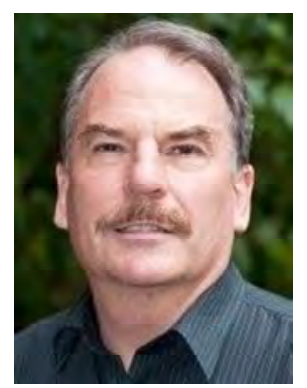

Stephen G Pyne received his Ph.D. (with Lew Mander) in 1979 from the Australian National University. After postdoctoral research fellowships at Purdue University (with P. Fuchs) and Harvard (with E. J. Corey) he was appointed as a lecturer at the University of Wollongong in 1985. In 1998 he was appointed to
Professor. He won the A. J. Birch Medal for excellence in Organic Chemistry Research, from the Organic Doivisiósbeqharopol Australian Chemical Institute (RACl) in 2012 and the Archibald Ollé Prize for Chemical Literature, from the RACl, in 2015. His research interests include, natural product synthesis, organoboron reagents, metal-catalysed reactions, natural product chemistry, and antibacterial drug discovery and development. 